\title{
Realizing Catalytic Acetophenone Hydrodeoxygenation with Palladium-Equipped Porous Organic Polymers
}

\author{
Paul, Ratul; Shit, Subhash Chandra; Fovanna, Thibault; Ferri, Davide; Srinivasa Rao, Bolla; \\ Gunasooriya, G.T. Kasun Kalhara; Dao, Duy Quang; Le, Quyet Van; Shown, Indrajit; Sherburne, Matthew \\ P.
}

Total number of authors:

12

\section{Published in:}

ACS Applied Materials and Interfaces

Link to article, DOI:

10.1021/acsami.0c16680

Publication date:

2020

Document Version

Peer reviewed version

Link back to DTU Orbit

Citation (APA):

Paul, R., Shit, S. C., Fovanna, T., Ferri, D., Srinivasa Rao, B., Gunasooriya, G. T. K. K., Dao, D. Q., Le, Q. V., Shown, I., Sherburne, M. P., Trinh, Q. T., \& Mondal, J. (2020). Realizing Catalytic Acetophenone Hydrodeoxygenation with Palladium-Equipped Porous Organic Polymers. ACS Applied Materials and Interfaces, 12(45), 5055050565. https://doi.org/10.1021/acsami.0c16680

\section{General rights}

Copyright and moral rights for the publications made accessible in the public portal are retained by the authors and/or other copyright owners and it is a condition of accessing publications that users recognise and abide by the legal requirements associated with these rights.

- Users may download and print one copy of any publication from the public portal for the purpose of private study or research.

- You may not further distribute the material or use it for any profit-making activity or commercial gain

- You may freely distribute the URL identifying the publication in the public portal 
This document is the accepted manuscript version of the following article: Paul, R., Shit, S.C., Fovanna, T., Ferri, D., Rao, B.S., Gunasooriya, G. T.K.K., ... Monda1, J. (2020). Realizing catalytic acetophenone hydrodeoxygenation with palladium-equipped porous organic polymers. ACS Applied Materials and Interfaces, 12 (45), 50550-50565. https://doi.org/10.1021/acsami .0c16680

\section{Realizing Catalytic Acetophenone Hydrodeoxygenation with Palladium Equipped Porous-Organic-Polymer}

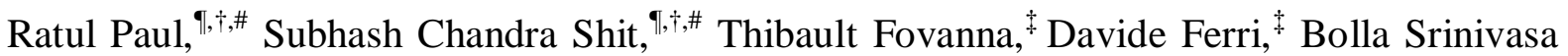
Rao, ${ }^{\dagger}$ G. T. Kasun Kalhara Gunasooriya, ${ }^{ \pm}$Duy Quang Dao, ${ }^{\prime}$ Quyet Van Le, ${ }^{\perp}$ Indrajit Shown, ${ }^{\theta}$ Matthew P. Sherburne, ${ }^{\S, \Delta}$ Quang Thang Trinh, ${ }^{*, 1, \Pi}$ and John Mondal ${ }^{*, l, \dagger}$

${ }^{\mathrm{II}}$ Catalysis \& Fine Chemicals Division, CSIR-Indian Institute of Chemical Technology, Uppal Road, Hyderabad-500007, India.

${ }^{\dagger}$ Academy of Scientific and Innovative Research (AcSIR), Ghaziabad-201002, India.

Paul Scherrer Institut, CH-5232 Villigen, Switzerland.

${ }^{ \pm}$Catalysis Theory Center, Department of Physics, Technical University of Denmark, DK2800 Lyngby, Denmark.

'Institute of Research and Development, Duy Tan University, 03 Quang Trung, Danang 550000, Viet Nam.

${ }^{\perp}$ Department of Materials Science and Engineering, Korea University, 145 Anam-ro, Seongbuk-gu, Seoul 02841, Republic of Korea

${ }^{\theta}$ Amrita Centre for Nanosciences and Molecular Medicine, Amrita Institute of Medical Sciences, Amrita Vishwa Vidyapeetham, Kochi-682041, Kerala, India.

${ }^{\S}$ Materials Science and Engineering Department, University of California, Berkeley, Berkeley, California 94720, United States.

${ }^{\Delta}$ A Singapore Berkeley Research Initiative for Sustainable Energy, Berkeley Educational Alliance for Research in Singapore, 1 Create Way, 138602, Singapore.

${ }^{\Pi}$ Cambridge Centre for Advanced Research and Education in Singapore (CARES), Campus for Research Excellence and Technological Enterprise (CREATE), 1 Create Way, 138602, Singapore.

\#These two authors have equally contributed in this manuscript.

\section{Corresponding Authors}

*E-mail: trinhquangthang @duytan.edu.vn (Q.T.T.).

*E-mail: johncuchem@gmail.com; johnmondal@iict.res.in (J.M.) 
ABSTRACT: Porous-Organic-Polymers (POPs) constructed through covalent bonds have raised tremendous research interest because of their suitability to develop robust catalysts and their successful production with improved efficiency. In this work, we have designed and explored the properties and catalytic activity of template-free construction hydroxy $(-\mathrm{OH})$ group enriched porous-organic-polymer (Ph-POP) bearing functional Pd nanoparticles (Pd-NPs) by one-pot condensation of phloroglucinol (1,3,5-trihydroxybenzene) and terephthalaldehyde followed by solid phase reduction with $\mathrm{H}_{2}$. The encapsulated Pd-NPs rested within welldefined POP nanocages and remained undisturbed from aggregation and leaching. This polymer hybrid nanocage Pd@Ph-POP is found to enable efficient liquid-phase hydrodeoxygenation (HDO) of acetophenone (AP) with high selectivity (99\%) of ethylbenzene (EB) and better activity than its $\mathrm{Pd} @ \mathrm{Al}_{2} \mathrm{O}_{3}$ counter-part. Our investigation demonstrates a facile, scalable, catalyst-template free methodology for developing novel porous-organic-polymer catalysts and next generation efficient greener chemical processes from platform molecules to value-added chemicals. With the aid of comprehensive in situ ATR-IR spectroscopic experiments, it is suggested that EB can be more easily desorbed in solution, reflecting from the much weaker but resolved signals at $1494 \mathrm{~cm}^{-1}$ in Pd@Ph-POP compared to the $\mathrm{Pd} @ \mathrm{Al}_{2} \mathrm{O}_{3}$, which is the key-determining factor in favoring efficient catalytic mechanism. Density functional theory (DFT) calculations were performed to illustrate the detailed reaction network and to explain the high catalytic activity observed for the fabricated Pd@Ph-POP catalyst in the HDO conversion of AP to EB. All the hydrogenation routes, including the direct hydrogenation by surface hydrogen, the hydrogen transfer and the keto-enol pathway are evaluated, providing insights for the experimental observations. The presence of phenolic hydroxyl groups of the Ph-POP frame-structure facilitates the hydrogen shuttling mechanism for the dehydration from the intermediate phenylethanol, which was identified as the crucial step for the formation of the final product ethylbenzene. Besides, weaker binding of the desired product ethyl benzene and lower coverage of surface hydrogen atoms on Pd@Ph-POP, both contributed to inhibiting the over-hydrogenation reaction and explained well the high yield of EB produced during the HDO conversion of AP on Pd@Ph-POP in this study.

KEYWORDS: Porous-Organic-Polymer; Hydrodeoxygenation; Robust Heterogeneous Catalyst; ATR-IR, Density functional theory calculations (DFT) 


\section{INTRODUCTION.}

Extensive work has been devoted to the catalytic hydrogenation of carbonyl groups of organic derivatives owing to the importance of this transformation for the production of fine chemicals, pharmaceuticals, and cosmetics. ${ }^{1}$ Among these, acetophenone (AP) hydrogenation has gained particularly much attention because two hydrogenation products of AP, phenylethanol $(\mathrm{PhE})$ and ethylbenzene (EB) have notable applications: $\mathrm{PhE}$ has been employed to synthesize perfumery products and pharmaceuticals, ${ }^{2}$ while EB has been used as starting material for styrene production. ${ }^{3}$ AP hydrogenation is a complex multi-step reaction with the competitive hydrogenations of carbonyl group and aromatic ring and the concurrent hydrogenolysis of $\mathrm{PhE}^{4}$ and hence all these possible alternatives make it very challenging to selectively synthesise $\mathrm{PhE} / \mathrm{EB}$ from AP. So far, several catalytic systems based on $\mathrm{Pt},{ }^{5} \mathrm{Pd},{ }^{6} \mathrm{Ru},{ }^{7}$ $\mathrm{Cu}^{8}{ }^{8}$ have been reported for this selective reaction. However, these catalytic systems present issues associated with harsh reaction conditions like high hydrogen pressure and high temperature, as well as with metal leaching, which are big hurdle for practical application. Specifically, it has been observed that hydrogenation rate of $\mathrm{PhE}$ conversion to $\mathrm{EB}$ is favoured on Pd with increasing temperature above $373 \mathrm{~K} .{ }^{9}$ To overcome the mentions problems, among several approaches improvement in the catalysts support such as support acidity, porosity etc. have been taken into consideration. Generally, it has been observed that acidic supports encourage different type of reactions like dehydration/hydrogenolysis, hydrogenation, and hydrocracking etc. In this connection, Baiker and co-workers spotted that acidic and basic supports have significant influence on Pt metal catalyzed enantioselective hydrogenation of methyl benzoylformate and ketopantolactone. ${ }^{10}$ Later on, Chen et al. experimentally proved that catalytic activity of supported Pd catalysts for AP hydrogenation can be easily increased by regulating the acidity of the support because acidic supports can produce ionic effects on metal surfaces and affect the surface electronic properties which help in dissociation of hydrogen. $^{11}$

From the viewpoint of stability, surface area with adjustable pore size and prevention of leaching of metal or metal oxide NPs several nanoporous supports like ordered mesoporous $\mathrm{N}$-doped carbon, metal-organic-frameworks (MOFs) as well as porous organic polymers (POPs) have been employed. Porous-Organic-Polymers (POPs) have been regarded as potential support material in catalysis owing to highly cross linked rigid symmetric skeletons with higher mechanical and thermal stability, huge surface area, and suitable pore size distribu- 
tion. ${ }^{12-15}$ Moreover, selection of proper monomer, linker and synthetic strategy chemical environment and molecular connectivity of POPs can be easily tuned to enhancement catalytic activity by changing the electronic properties of the metal surface through interaction with metal NPs. ${ }^{16}$ POP frameworks comprising distinct rigid nanocage-like structures can offer a protecting shell with minimum surface coverage for encapsulation of single active sites, which would be advantageous compared to conventional small organic ligands or macromolecular ligands. ${ }^{17}$

In the effort to address these issues, we focused on exploring the encapsulation of Pd-NPs in the cavities of robust and stable Ph-POP with the aim to make Pd resistant to agglomeration and leaching and capable of chemoselective AP hydrogenation. The catalytic activity of this novel catalyst with closed architecture of the Ph-POP cage could be further boosted remarkably via the assembly of hydroxyl groups in the polymer support, which can eventually enhance surface acidity and achieve modulation of the electronic properties of the anchored Pd metal due to intrinsic synergistic effect between Ph-POP and Pd-NPs. Furthermore, to reveal the intrinsic role of the $\mathrm{Pd}$ on $-\mathrm{OH}$ interface in the catalytic $\mathrm{HDO}$ reaction of $\mathrm{AP}$, we have performed in situ attenuated total reflection infrared (ATR-IR) spectroscopy and density functional theory (DFT) investigations.

\section{EXPERIMENTAL AND COMPUTATIONAL DESCRIPTION.}

\subsection{Materials preparation.}

Phloroglucinol, terephthalaldehyde, palladium acetate $\left(\mathrm{Pd}(\mathrm{OAc})_{2}\right)$, acetophenone (AP) and hydrochloric acid $(\mathrm{HCl})$ were purchased from Sigma-Aldrich and used as received unless noted otherwise. 1, 4-dioxane, dichloromethane (DCM), isopropanol and tetrahydrofuran (THF) solvents were all dried before using in reaction.

\subsection{Synthesis of hydroxy (-OH) group enriched Porous-Organic-Polymer (Ph-POP).}

The hydroxy rich porous organic polymer (Ph-POP) was prepared following the previously described method by Lu et al. ${ }^{18}$ First, phloroglucinol (250mg, 2 mmol) and terephthalaldehyde (200mg, $10.5 \mathrm{mmol}$ ) were mixed together in $10 \mathrm{~mL} \mathrm{1,4-dioxane} \mathrm{and} \mathrm{subsequently,} 1 \mathrm{ml}$ of concentrated $\mathrm{HCl}(\mathrm{aq})(37 \%)$ was added drop wise to the solution. Then the reaction mixture was allowed to stir at $100{ }^{\circ} \mathrm{C}$ for overnight. After cooling at room temperature yellowish brown solid was isolated by filtration and washed thoroughly using THF and dried under vacuum for $12 \mathrm{~h}$ and designated as Ph-POP. 


\subsection{Synthesis of Pd-NPs impregnated Porous-Organic-Polymer (Pd@Ph-POP).}

In a typical synthetic procedure, $200 \mathrm{mg} \mathrm{Ph}-\mathrm{POP}$ was dispersed in $80 \mathrm{~mL}$ DCM via sonication for $15 \mathrm{~min}$. Then in $20 \mathrm{~mL}$ DCM solvent $\mathrm{Pd}(\mathrm{OAc})_{2}(0.05 \mathrm{~g}, 0.2 \mathrm{mmol})$ was dissolved which was added to the previous solution and the resulting mixture was stirred at $60{ }^{\circ} \mathrm{C}$ for 24h. The as-obtained brown $\mathrm{Pd}(\mathrm{II}) @ \mathrm{Ph}-\mathrm{POP}$ composite was isolated using a rotatory evaporator. After that the brown solid composite was reduced through heat treatment in a stream of $\mathrm{H}_{2} / \mathrm{N}_{2}\left(10 \% \mathrm{H}_{2}, 100 \mathrm{~mL} \min ^{-1}\right)$ at $200{ }^{\circ} \mathrm{C}$ for $4 \mathrm{~h}$. The resulting dark brown solid was collected and designated as Pd@Ph-POP.

\section{4. in situ ATR-IR study of AP hydrogenation.}

Thin layers of $\mathrm{Pd} @ \mathrm{Al}_{2} \mathrm{O}_{3}$ and Pd@Ph-POP (5 mg) for attenuated total reflection infrared (ATR-IR) spectroscopy were obtained from drop casting the corresponding suspension in distilled water on a $\mathrm{ZnSe}$ internal reflection element (IRE, $45^{\circ}, 52 \times 20 \times 2 \mathrm{~mm}$ ). The coated IRE was assembled within a homemade cell that was mounted vertically on a commercial mirror unit (Specac) inserted in the sample compartment of a Bruker Vertex 70 spectrometer. All spectra were acquired at $4 \mathrm{~cm}^{-1}$ resolutions by co-adding 20 interferograms at $80 \mathrm{kHz}$ scanner velocity with a liquid $\mathrm{N}_{2}$ cooled $\mathrm{HgCdTe}$ detector. The temperature of the cell was controlled using a thermostat (Huber).

Prior to experiment, the catalyst layer was equilibrated with solvent flow for $60 \mathrm{~min}$ at $60^{\circ} \mathrm{C}$, followed by reduction with $\mathrm{H}_{2}$-saturated solvent for $30 \mathrm{~min}$. Pyridine adsorption was carried out by admitting a solution of pyridine in cyclohexane $(5 \mathrm{mM})$ at ambient temperature for $30 \mathrm{~min}$ followed by desorption with cyclohexane solvent. Concentration modulation experiments were carried out after equilibrating the reduced catalyst layer with a $\mathrm{H}_{2}$-saturated solution of AP $(2 \mathrm{mM})$ at $60^{\circ} \mathrm{C}$ by alternating five pulses of $\mathrm{H}_{2}$-saturated solvent $(60 \mathrm{~s} ; 30$ spectra) to five pulses of $\mathrm{H}_{2}$-saturated AP solution ( $60 \mathrm{~s} ; 30$ spectra) while recording ATR-IR spectra. Isopropanol was used as the solvent. After measurement, the spectra measured along time were treated using phase sensitive detection (PSD) ${ }^{19}$ enabling identifying only the signals of species (adsorbed and dissolved) that responded to the AP pulses in the $\mathrm{H}_{2}$-saturated isopropanol.

\subsection{Catalytic activity test for acetophenone (AP) hydrogenation.}

At first, AP (0.12 ml, 1mmol), Pd@Ph-POP catalyst (15 mg), and isopropanol (30 mL) were loaded in a $50 \mathrm{~mL}$ dry stainless-steel autoclave (Parr Instrument). Then, the reactor was flushed with hydrogen several times to remove dissolved $\mathrm{O}_{2}$ or air followed by pressurizing up to 0.5 bar $\mathrm{H}_{2}$. Finally, the temperature of the autoclave was set at $60{ }^{\circ} \mathrm{C}$ and stirring was 
started $(800 \mathrm{rpm})$ to initiate the reaction. After cooling at room temperature, the catalyst was collected from the reaction mixture through centrifugation and washed with methanol. The reaction mixture was analyzed by a gas chromatograph (Shimadzu 2010) equipped with a flame ionization detector using a INNOWax capillary column (diameter: $0.25 \mathrm{~mm}$, length: 30 m). The products were also identified by GC-MS (Shimadzu, GCMS-QP2010S).

\subsection{Computational details.}

All the calculations have been performed using a plane-wave basis set with a cut-off kinetic energy of $450 \mathrm{eV}$ and the projector-augmented wave (PAW) scheme implemented in the ab-initio total-energy and molecular-dynamics program VASP (Vienna ab-initio simulation program) developed at the Fakultät für Physik of the Universität Wien. ${ }^{20-21}$ To describe correctly the concerted effect of both covalency and van der Waals interaction between aromatic compounds and transition metal surface, ${ }^{22-23}$ the optimized Becke88 functional (optB88) including the non-local vdW-DF correlation (optB88-vdW exchange-correlation function) developed by Klimeš et al. ${ }^{24}$ was used throughout all the calculations. We have computed the binding energy of acetophenone on Pd surface using both the conventional Perdew-BurkeErnzerhof (PBE) and optB88-vdW functionals. The binding energy of acetophenone on Pd surface obtained from DFT calculations using PBE and optB88-vdW functionals were -123 and $-238 \mathrm{~kJ} / \mathrm{mol}$, respectively. This huge difference obtained demonstrates the need to use the proper optB88-vdW functional for DFT simulation of reactions involving aromatic compounds on Pd surfaces.

Optimized lattice constant for Pd using the optB88-vdW functional was $3.94 \AA$, which agrees very well with experimental value of $3.88 \AA^{25}$ The Pd catalyst was modelled by a periodic four-layers $\mathrm{p}(4 \times 4) \operatorname{Pd}(111)$ slab, and the vacuum thickness of $20 \AA$ was applied above the topmost layer to avoid the interactions between repeated slabs. As was reported in literature, ${ }^{26-27}$ the use of terrace sites $\operatorname{Pd}(111)$ for modelling surface active sites of large nanoparticle (larger than $5 \mathrm{~nm}$ ) is an appropriate choice due to the dominate exposure of those terrace facets, which is consistent with the presence of $\operatorname{Pd}(111)$ surface detected in the high resolution TEM images (shown later in Figure 2f). Furthermore, acetophenone adsorbs much weaker on step sites than terrace sites (Supporting Information, Figure S24), resulting in the lower activity of step sites for acetophenone activation. Therefore, although step sites could be presented at some extend in our Pd catalyst, due to (i) their activities are less than terrace sites and (ii) their presence are much smaller than the presence of terrace site, it provides another supportive justification for using $\operatorname{Pd}(111)$ to represent the active sites of the catalyst 
in this study. For all the calculations, two topmost layers and the adsorbates were allowed to fully relaxed, while the atoms in the remaining bottom layers were fixed at their bulk optimized lattice constant to make the computational simulations more efficient while not have any influence to the accuracy. ${ }^{28}$ The Brillouin zone was sampled with the $3 \times 3 \times 1$ MonkhorstPack grid. Increasing the slab thickness to five layers, the inter-slab spacing to $30 \AA$, or the grid to $(5 \times 5 \times 1)$ only changed the calculated binding energies by less than $5 \mathrm{~kJ} / \mathrm{mol}$. Transition states of the reactions occurred during the HDO conversion of acetophenone were located using the Climbing-Nudged Elastic Band (Cl-NEB) method ${ }^{29}$ and is confirmed by only one imaginary vibrational frequency from frequency calculations.

\section{RESULTS AND DISCUSSION:}

\subsection{Material characterization.}

In this study, we have adopted a molecular template and catalyst free cost-effective approach to develop hydroxyl (-OH) group enriched porous-organic-polymer (Ph-POP) by onepot condensation of phloroglucinol (1,3,5-trihydroxybenzene) and terephthalaldehyde (Scheme 1) results in a three-dimensional phenol prosperous POP network having Bakelite type chemistry of forming C-C bonds, as previously described by Kanatzidis and coworkers. ${ }^{30}$ Solid phase $\mathrm{H}_{2}$ reduction technique was used to reduce $\mathrm{Pd}(\mathrm{II}) @ \mathrm{Ph}-\mathrm{POP}$ that was obtained by impregnating of $\mathrm{Ph}-\mathrm{POP}$ in a solution of $\mathrm{Pd}(\mathrm{OAc})_{2}$ in dichloromethane, provides the desired Pd@Ph-POP. The as-synthesized Ph-POP and Pd@Ph-POP were comprehensively characterized by wide angle powder X-ray diffraction pattern (PXRD), ${ }^{13} \mathrm{C}-\mathrm{CP}$ Solid state MAS NMR, X-ray photoelectron spectroscopy (XPS), Transmission Electron Microscopy (TEM), field emission scanning electron microscopy (FE-SEM), $\mathrm{N}_{2}$ physisorption and FT-IR spectroscopy. Thermal stability of the as-synthesized Ph-POP was measured by heating the material from $25{ }^{\circ} \mathrm{C}$ to $600{ }^{\circ} \mathrm{C}$ temperature under $\mathrm{N}_{2}$ atmosphere as experimentally evidenced by the thermogravimetric analysis (Figure S1, SI) associated with two sharp breakdown of percentage weight loss at $140{ }^{\circ} \mathrm{C}$ and $420^{\circ} \mathrm{C}$, respectively. 

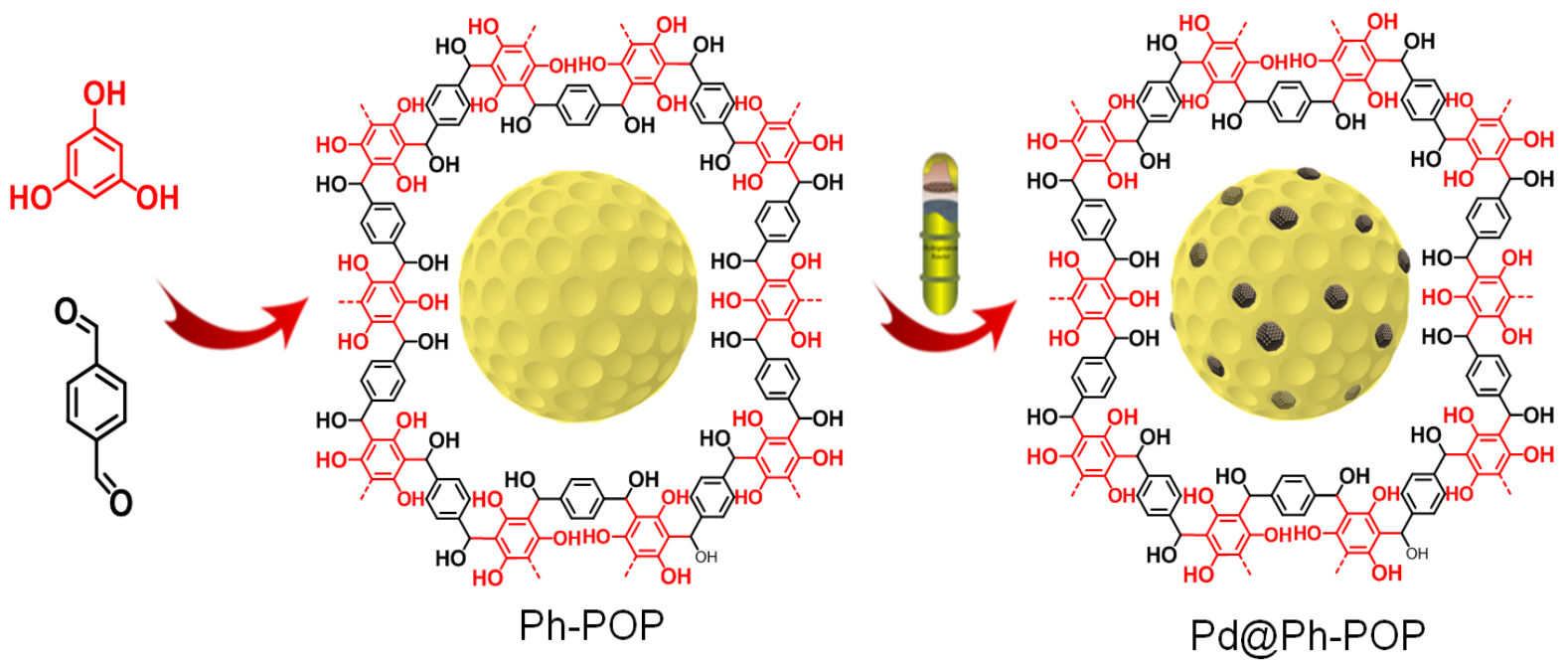

Scheme 1: Sequential catalyst and molecular-template free syntheticillustration of newly designed Pd Equipped Porous-Organic-Polymer Pd@Ph-POP.

An exothermic mass loss of $\sim 15 \mathrm{wt} . \%$ up to $140{ }^{\circ} \mathrm{C}$ is observed which could be attributed to the evaporation of surface water and entrapped solvent molecules (1,4-dioxane \& THF) inside the polymeric cage. This suggests that some structural vacancies may exist that enable to load and stabilize Pd-NPs inside the porous cage. At higher temperature $\left(\sim 420^{\circ} \mathrm{C}\right)$, a considerable weight loss ( $35 \mathrm{wt} . \%)$ occurs which may be due to the collapse of entire organic framework into small molecules and the release of free hydroxyl group in the form of $\mathrm{CO}_{2}$ and $\mathrm{H}_{2}$. No further clear weight loss was observed with continuous heating accounting for the excellent thermal and mechanical stability of the Ph-POP. We have found 56.13 wt.\% carbon $(\mathrm{C})$ and 5.55 wt.\% hydrogen $(\mathrm{H})$, respectively, in Ph-POP as evaluated by elemental $(\mathrm{C}$, $\mathrm{H}, \mathrm{N}$ ) analysis (Table S1, SI). 100\% degree of cross-linking with successful condensation for an ideal POP framework has been confirmed with the experimental $\mathrm{C}, \mathrm{H}, \mathrm{N}$ results which appeared to be lower than the corresponding calculated theoretical values. A little variation in the elemental analysis of Pd@Ph-POP compared with the parent Ph-POP possibly refers to the inclusion of guest molecules inside the cavity by the coordination ability of the phenolic $\mathrm{O}$ atom. The loading amount of Pd in Pd@Ph-POP, as determined by Inductive Couple Plasma-Atomic Emission Spectroscopy (ICP-AES) measurement is found to be 0.205 mmol.g $\mathrm{g}^{-1}$. In order to estimate surface acidity content of as-synthesized $\mathrm{Ph}-\mathrm{POP}, \mathrm{NH}_{3}-\mathrm{TPD}$ (temperature-programmed desorption) analysis was performed. The single sharp strong desorption peak positioned at $453{ }^{\circ} \mathrm{C}$ (Figure S2, SI) could be recognized to the strongly chemisorbed ammonia which can be used to calculate the surface acidity. Surface acid strength of $\mathrm{Ph}-\mathrm{POP}$ has been evaluated to be $1.603 \mathrm{mmol} / \mathrm{g}$, eventually revealed to the strong acidic sites which arise from the large number of phenolic -OH groups in the polymer network. The ex- 
perimental result suggested that the phenolic - $\mathrm{OH}$ groups could easily modify the surface acidity of the POP which can impact on the catalytic performance of Pd thereby modulating surface electron density, which will be discussed in the following sections. Pyridine adsorption (Figure S3, SI) further also confirmed the presence of extensive Brönsted acidity in the case of Pd@Ph-POP.

Molecular connectivity and chemical environment of carbon nuclei in the respective $\mathrm{Ph}$ POP has been evaluated by conducting ${ }^{13} \mathrm{C}-\mathrm{CP}$ solid state MAS NMR analysis (Figure 1). The resonance signal appeared at $\delta=36.6 \mathrm{ppm}$ could be assigned to the tertiary or methyl bridge carbon as formed by the condensation reaction between - $\mathrm{CHO}$ functional group and phloroglucinol $o$-carbons. The broad signal located at $\delta=109.6 \mathrm{ppm}$ corresponds to the phloroglucinol $o$-carbons that participated in the condensation reaction. The weak peaks at $\delta=$ 25.3 and 67.8 ppm clearly specify trapped THF solvent inside the porous cage of Ph-POP. The unreacted phloroglucinol $o$-carbons has been established with the existence of the signal at $\delta=98.4 \mathrm{ppm}$, in good agreement with the previous report by Lu et al. ${ }^{31}$ The MAS NMR spectrum of Ph-POP also (Figure 1a) exhibits two sharp signals emerging at $\delta=127.9 \&$ $153.4 \mathrm{ppm}$, respectively, correspond to the aromatic \& phenoxy carbons, respectively. On the other hand, the peak relative to the resonance at $\delta=134.7 \mathrm{ppm}$ which is consistent with the higher content of aromatic carbons. We have also noticed similar kind of resonance signals with somewhat overlapped rotation side bands in the solid-state ${ }^{13} \mathrm{C}$ CP MAS NMR spectrum of Pd@Ph-POP (Figure 1a), revealing that the structural integrity remains preserved after successful Pd-NPs loading.

(a)

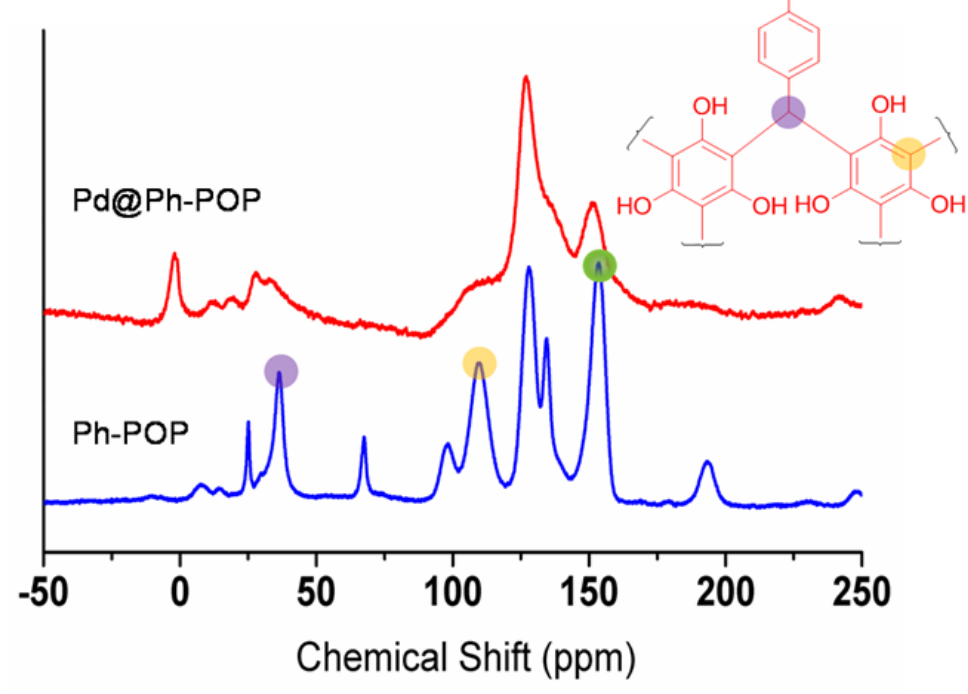

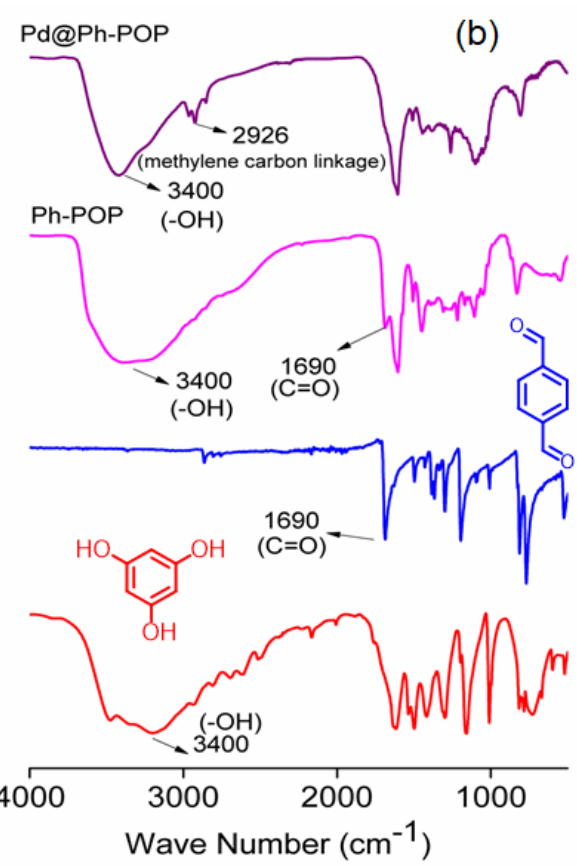


Figure 1: ${ }^{13} \mathrm{C}-\mathrm{CP}$ solid state MAS NMR analysis (a) and FT-IR spectroscopy (b) of Ph-POP and Pd@Ph-POP, respectively.

The polymeric framework construction with covalent bonding in Ph-POP has been studied by FT-IR spectroscopy (Figure 1b). The broad absorption band positioned at $\sim 3400 \mathrm{~cm}^{-1}$ is attributed to the characteristic stretching vibration mode of the $\mathrm{O}-\mathrm{H}$ bond of phloroglucinol. In particular, the distinctive vibrations at $1445-1600 \mathrm{~cm}^{-1} \& 1219 \mathrm{~cm}^{-1}$ could be recognized to the presence of the benzene skeleton vibrations and C-C-O asymmetric stretching modes, respectively. ${ }^{32}$ The concomitant appearance band at region of $\sim 2926 \mathrm{~cm}^{-1}$ provides clear evidence for the formation of methyne carbon linkage in Ph-POP. While an obvious stretching vibration mode of aldehyde group at $\sim 1697 \mathrm{~cm}^{-1}$ with very poor intensity was observed which unambiguously indicated that the few aldehyde groups remain unreacted as supported by ${ }^{13} \mathrm{C}$ MAS NMR spectrum where strong peak present in terepthaldehyde unit. The wideangle powder XRD (PXRD) pattern (Figure S4, SI) exhibited one broad diffraction peak at $2 \theta=21^{\circ}$, attributable to the $\Pi$-stacking of the aromatic building blocks in small domains. Meanwhile, the PXRD pattern of Pd@Ph-POP demonstrated that the Pd ${ }^{0}$-NPs (JCPDS no. 46-1043) with face-centered cubic ( $f c c$ ) lattice arrangement were grown with the maximum surface exposure at the external surface where the three distinguishable crystalline diffraction peaks could be nicely indexed with $2 \theta=40.1^{\circ} \mathrm{Pd}(111), 46.2^{\circ} \mathrm{Pd}(200) \& 67.2^{\circ} \mathrm{Pd}(220)$, respectively. ${ }^{13}$ We have also performed the PXRD pattern of the reference catalysts including $\mathrm{Al}_{2} \mathrm{O}_{3}\left(\mathrm{Pd} / \mathrm{Al}_{2} \mathrm{O}_{3}\right)$ and carbon supported Pd-NPs (Pd/C) and bare Pd-NPs (Figure S5). Interestingly, for three reference catalysts similar diffraction peaks having $2 \theta$ values $40.1^{\circ}, 46.2^{\circ}$ and $67.2^{\circ}$, confirming the presence of $\mathrm{Pd}^{0}$ nanoparticle. ${ }^{13}$ In addition, we have observed diffraction peak at $26.4^{\circ}$ for $\mathrm{Pd} / \mathrm{C}$ samples, indicating presence of carbons ${ }^{33}$ and diffraction peaks at $71.8^{\circ}, 49.1^{\circ}, 38.3^{\circ}, 28.8^{\circ}$ and $18.7^{\circ}$ for $\mathrm{Pd} / \mathrm{Al}_{2} \mathrm{O}_{3}$, signaling the presence of $\gamma-\mathrm{Al}_{2} \mathrm{O}_{3}$ phase. ${ }^{34}$ In order to have insight about the permanent porosity of those materials we have performed $\mathrm{N}_{2}$-adsoprtion/desorption analysis at $77 \mathrm{~K}$ (Figure S6). $\mathrm{N}_{2}$ sorption isotherms of both Ph-POP \& Pd@Ph-POP with no prominent hysteresis loop correspond to high $\mathrm{N}_{2}$ uptake at very low $P / P_{0}$ region followed by rapid uptake at the high-pressure region of $P / P_{0}>0.4$, could be categorized as typical type II isotherm, according to the IUPAC classification, characteristic for the existence of interparticle void spaces within the Ph-POP-based materials. The specific BET surface areas of the Ph-POP \& Pd@Ph-POP materials were found to be 570 and 267 $\mathrm{m}^{2} \mathrm{~g}^{-1}$, respectively. From this observation we can definitely conclude that the dialdehyde molecule underwent condensation with phloroglucinol to construct highly cross-linked organic framework comprising with higher porosity and inherent surface area. Both partial pore oc- 
cupancy and mass increment after Pd-NPs entrapment into the porous channel suggests to the shrinkage of pore width in Pd@Ph-POP, resulting in the significant reduction in the BET surface area but without alteration of isotherms shape. The total pore volumes of Ph-POP and Pd@Ph-POP were measured to be 0.59 and $0.47 \mathrm{~cm}^{3} \mathrm{~g}^{-1}$, respectively. Non local density functional theory (NLDFT) fitting of the adsorption branches model revealed a narrow pore size distribution with the average pore size of $1.68 \mathrm{~nm}$, which is a clear indication of abundant microporosity in the material (Figure S6b). No any obvious change in the pore size $(1.48 \mathrm{~nm})$ for Pd@Ph-POP could be noticed, which may be on account of the fact that the random diffusion and space-filling within the branching fragments of the extended repeating units of POP unit.

We have conducted SEM \& TEM microscopy study in various magnifications to evaluate the morphology of as-synthesized Ph-POP, shape, distribution and location of entrapped PdNPs inside the Ph-POP matrix. Irregular nanospheres having diameter of about 0.4-0.6 $\mu \mathrm{m}$ (Figure S7a, b \& c) are strongly interconnected together leading to the construction of continuous microporous polymeric Ph-POP framework. The visual impression from the high magnification SEM image of Ph-POP (Figure S7c) is that the external surface of these spherical particles appeared to be very smooth in nature. Figure S7b describes that a large number of tiny particles with diameter $\sim 610 \mathrm{~nm}$ got randomly self-assembled together creating a cluster island with some cavities or interparticle porosity as supported by the existence of $\mathrm{N}_{2}$ condensation close to atmospheric pressure in the adsorption measurements. On the other hand, it is noticed that the shape of Pd@Ph-POP sample composed with the well-defined nanospheres (250-250 nm) tightly adhered with each other (Figure S7d). It could also be observed that the spherical Pd particles having diameter $\sim 25-30 \mathrm{~nm}$ were closely packed on the external surface of the as-synthesized Ph-POP making the surface rough in nature as revealed from the close inspection of SEM images (Figure S7e \& f), and they look like gigantic clusters of nanoparticles. We could certainly emphasize that the architectural feature with shape of the Ph-POP can be well-retained after Pd-NPs incorporation with a little enhancement in the particle size (400-600 nm) (Figure S7e). 


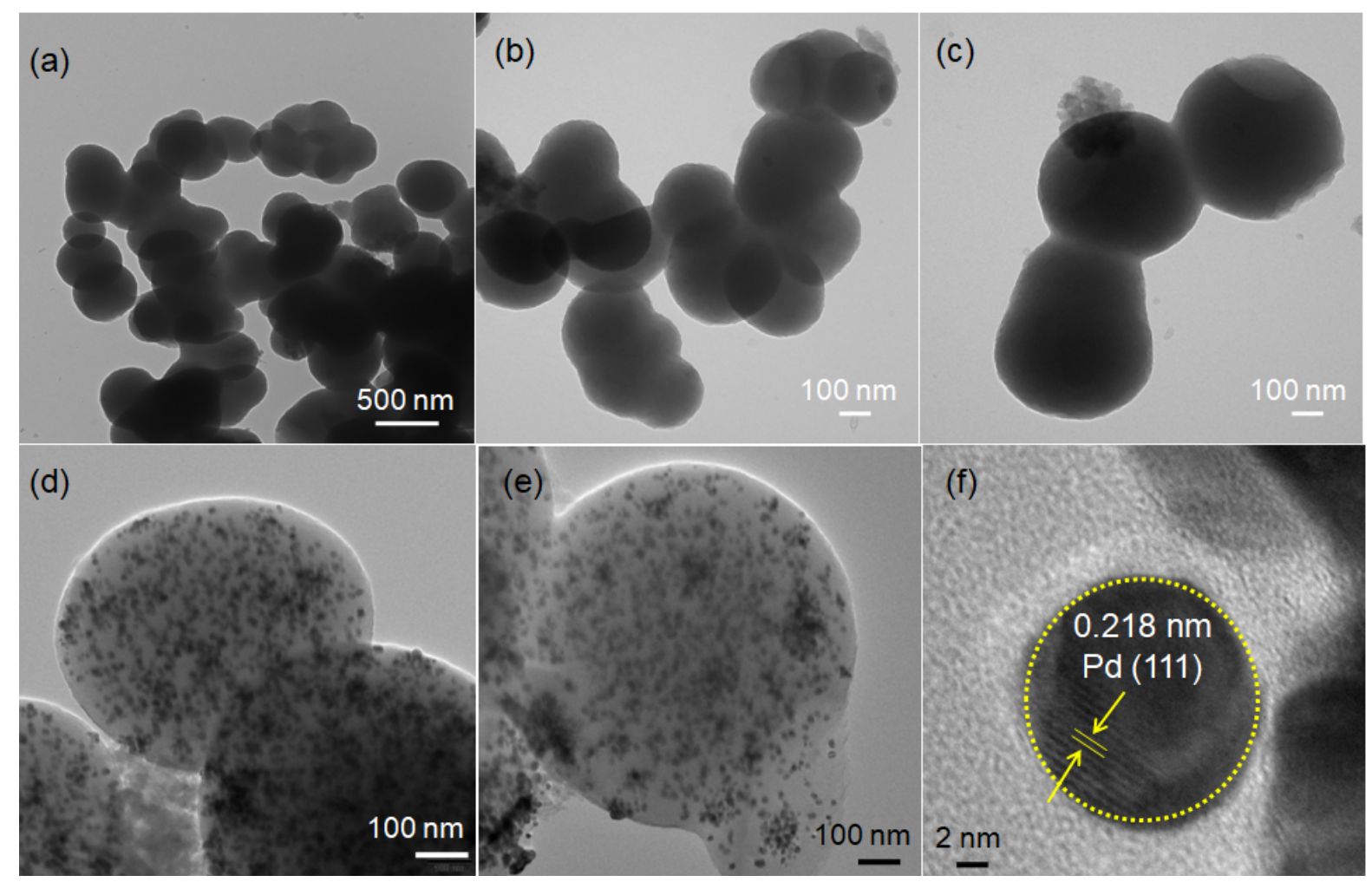

Figure 2: TEM images of as-obtained Ph-POP (a, b \& c) and Pd@Ph-POP (d \& e), respectively. (f) HR-TEM image of Pd@Ph-POP.

Recorded TEM images of Ph-POP (Figure 2a, b \& c) demonstrated the formation of disordered spheres like morphology varying diameter $\sim 400-500 \mathrm{~nm}$ are clumped entirely, which is in good agreement with the previous SEM results. We could also define that the porous organic Ph-POP framework was interconnected with each other by a large number of densely packed spheres (Figure $2 \mathrm{~b} \& \mathrm{c}$ ) assisted by the covalent chemical bonding and as well as through hydrogen bonding between the phloroglucinol - $\mathrm{OH}$ functional groups. All the TEM images of the Pd@Ph-POP (Figure 2d \& e and Figure S8, SI) unambiguously demonstrated that the spherical shape of the Ph-POP remains fairly constant after successful impregnation of Pd-NPs with slightly increase in the particle size $(650-750 \mathrm{~nm})$. A moderately homogeneous distribution of black colored Pd-NPs spherical in shape with average sizes of $6.4 \pm 0.4$ $\mathrm{nm}$ to $12.3 \pm 0.3 \mathrm{~nm}$ are discovered on the porous carbonaceous matrix from the TEM images (Figure $2 \mathrm{~d} \& \mathrm{e}$ ). The particle size distribution histogram profile is provided in Figure S9, SI. The Pd-NPs are mainly located in the external shell, as depicted by the transmission electron microscope (TEM) analysis, revealing to the more surface exposure of catalytic active sites making it additionally easy accessible reaction sequences. Pyrolysis treatment under $\mathrm{H}_{2} / \mathrm{Ar}$ atmosphere at high temperature may trigger diffusion of Pd-species from cores followed by deposition onto the surface with the smaller disintegration of nanospheres, consistent with the previous report by Schüth et al. ${ }^{35}$ Closer view of the HR-TEM image (Figure $2 \mathrm{f}$ ) demon- 
strates the well-defined inter-planar lattice spacing of about $0.218 \mathrm{~nm}$, attributable to the (111) lattice spacing of the face-centered cubic $(f c c)$ arrangement of the $\mathrm{Pd}^{0}-\mathrm{NPs} .{ }^{13}$ Energy dispersive X-ray (EDX) analysis (Figure S10, SI) of the particular selected area from the FESEM image consists of spectrum, representing abundance of each detected element in that specific area. The elemental composition of each element in weight \% $(\mathrm{C}, \mathrm{O} \& \mathrm{Pd})$ of the catalyst has been provided in the respective spectrum accordingly. We have also evaluated morphology study of reference catalysts. TEM images clearly exhibit the presence of black Pd nanoparticles in $\mathrm{Pd} / \mathrm{Al}_{2} \mathrm{O}_{3}$ (Figure S11 a-d), Pd/C (Figure S11 e-h), and bare Pd samples (Figure S11 i-l) with mean particle sizes of 9.41 $\pm 0.5,8.9 \pm 0.33$, and $20.71 \pm 0.25 \mathrm{~nm}$, respectively. Among three reference catalysts, there is clear aggregation of palladium nanoparticles in bare $\mathrm{Pd}$ samples and poorer dispersion of nanoparticles in $\mathrm{Pd} / \mathrm{Al}_{2} \mathrm{O}_{3}$ and $\mathrm{Pd} / \mathrm{C}$ samples compared to Pd@Ph-POP. Consequently, we have observed greater catalytic activity of Pd@Ph-POP towards acetophenone hydrodeoxygenation compared to other three catalysts which could be due to the fact that the oxygen rich Ph-POP framework having higher surface area could help in stabilizing and dispersing the Pd-NPs through synergistic interaction of oxygen units of Ph-POP and Pd-NPs. Crystalline features of Pd-NPs in the corresponding samples have been studied upon closer inspection with HR-TEM images (Figure S11 k \& 1) which demonstrate that the distinguished lattice fringes having a d-spacing of about $0.234 \mathrm{~nm}$ for the Pd-NPs, assigned to the (111) lattice spacing of the face-centered cubic $(f c c)$ arrangement of the $\mathrm{Pd}^{0}$ nanoparticles. Also, characteristic bright rings associated with distinct spots are clearly observed in the selected area electron diffraction (SAED) patterns (Figure S11) of reference catalysts, which could be readily indexed to the corresponding (111) crystalline reflections planes of $f c c \mathrm{Pd}$.
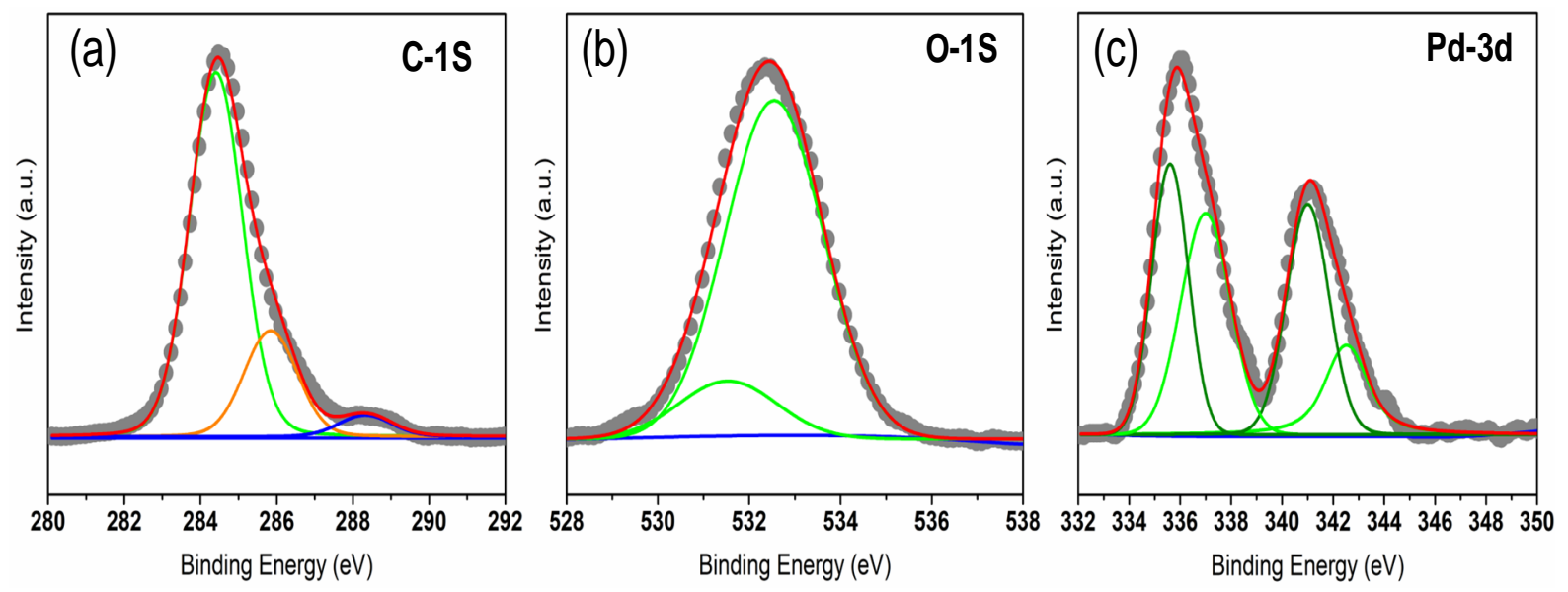

Figure 3: XP Spectrum of C-1s (a), O-1s (b) and Pd-3d (c) of Pd@Ph-POP catalyst. 
To investigate the chemical composition and oxidation state, we have carried out X-ray photoelectron spectroscopy (XPS) study which is shown in Figure 3. XPS survey spectrum (Figure S12, SI) exhibited four characteristic binding energy peaks among which two peaks at around 284.9 and $530.8 \mathrm{eV}$ which corresponds to $\mathrm{C} 1 \mathrm{~s}$ and $\mathrm{O} 1 \mathrm{~s}$, respectively along with the Pd $3 d$ binding energies. The C-1s spectra (Figure 3a) can be deconvoluted into three different types of binding energies which could be recognized to three different type of bonding: the peak at $\sim 284.4 \mathrm{eV}$ is due to $\mathrm{C}=\mathrm{C}$ bond, $\sim 285.8 \mathrm{eV}$ for $\mathrm{C}-\mathrm{O}$ bond and $\sim 288.3 \mathrm{eV}$ for $\mathrm{C}=\mathrm{O}$ bond of unreacted phloroglucinol, respectively. ${ }^{36}$ In the high-resolution XPS spectrum of O 1s (Figure 3b) two different type of peaks centred at $\sim 531.5 \mathrm{eV}$ and $\sim 532.5 \mathrm{eV}$ confirm the presence of two different type of oxygen in the Pd@Ph-POP. The peak at $\sim 531.5 \mathrm{eV}$ corresponds to oxygen atom present in $\mathrm{C}=\mathrm{O}$ group of unreacted phloroglucinol. ${ }^{37}$ The peak at $\sim 532.5 \mathrm{eV}$ could be assigned to O-H group, indicating hydroxyl rich $\mathrm{Ph}-\mathrm{POP}$ unit which is in accordance with the reported work by Zhang et al. on the preparation of hydrophobic polyvinyl alcohol aerogel. ${ }^{38}$ Additionally, we have also performed XPS analysis of bare Ph-POP framework and compared O1s spectra of bare Ph-POP with Pd@Ph-POP which has been shown in Figure S13, SI. Clearly there is a distinct higher binding energy shift of around 0.62 eV in the O 1s XPS spectra of Pd@Ph-POP compared to bare Ph-POP. This could be due to the strong electronic synergistic interaction between oxygen atoms of Ph-POP with Pd-NPs making the Pd surface more electron rich which is in good agreement with the work reported by Mondal et al. ${ }^{39}$ Figure 3c exhibits the deconvoluted spectra of Pd 3d region where the peaks appearing at $\sim 335.6 \mathrm{eV}$ and $\sim 341.0 \mathrm{eV}$ correspond to $\mathrm{Pd} 3 \mathrm{~d}_{5 / 2}$ and $\mathrm{Pd} \mathrm{d}_{3 / 2}$, indicating the presence of $\mathrm{Pd}$ metal $(\mathrm{Pd}(0))$ in the catalyst. The peaks centred at $\sim 336.9 \mathrm{eV}$ and $\sim 342.5$ $\mathrm{eV}$ could be assigned to $\mathrm{Pd} 3 \mathrm{~d}_{5 / 2}$ and $\mathrm{Pd} 3 \mathrm{~d}_{3 / 2}$ confirms the higher oxidation state of $\mathrm{Pd}(\mathrm{Pd}$ (II)). This is in good agreement with the work by Wang et al. on explaining the enhancing the catalytic activity of Pd/Carbon Nanotubes for 4-Nitrophenol reduction. ${ }^{40}$

\subsection{Catalytic investigation.}

We have investigated the catalytic activity of our newly designed hydroxyl rich porous organic polymer anchored palladium nanocatalyst ( $\mathrm{Pd} @ \mathrm{Ph}-\mathrm{POP}$ ) and $\mathrm{Al}_{2} \mathrm{O}_{3}$ supported $\mathrm{Pd}$ catalyst ( $\mathrm{Pd} @ \mathrm{Al}_{2} \mathrm{O}_{3}$ ) where Pd loading in reference catalyst is $0.219 \mathrm{mmol.g} \mathrm{g}^{-1}$ as obtained by ICP-AES analysis, towards the chemoselective hydrogenation of acetophenone (AP) which is shown in Figure 4. Three possible pathways are involved in AP hydrogenation: (i) Hydrogenation of carbonyl group to produce 1-phenylethanol $(\mathrm{PhE})$ followed by dehydration to obtain ethylbenzene (EB) and then ethylcyclohexane (EC) by ring hydrogenation (pathway 1); (ii) hydrogenolytic C-O bond cleavage of corresponding alcohol to hydrocarbon (pathway 2); 
and, (iii) direct hydrogenolysis to $\mathrm{C}-\mathrm{C}$ of $\mathrm{C}-\mathrm{C}=\mathrm{O}$ bond (pathway 3). The hydrogenation of the phenyl group producing cyclohexylmethylketone (CMK) and then 1-cyclohexylethanol (CE) and finally ethylcyclohexane (EC) also represents a possible reaction pathway (Figure S14, SI). Evaluation of reactant and product distribution with the progress of the reaction as a function of reaction time over the Pd@Ph-POP and $\mathrm{Pd} @ \mathrm{Al}_{2} \mathrm{O}_{3}$ catalysts are provided in Figure $4 \mathrm{a}$ and $4 \mathrm{~b}$, respectively, which revealed that the AP hydrogenation to give EB follow strictly the pathway 1 (hydrogenation of carbonyl group to produce $\mathrm{PhE}$ followed by dehydration to obtain EB and then EC) as showed in Figure S14, SI.

Our initial study began by conducting a hydrogenation reaction of AP (120 mg, $1 \mathrm{mmol})$ with isopropanol $(30 \mathrm{~mL})$ under 0.5 bar hydrogen pressure at $60{ }^{\circ} \mathrm{C}$ in the presence of Pd@Ph-POP. The products were identified from the reaction mixture and analyzed by using a GC-FID detector with comparison to a reference samples. From Figure $4 \mathrm{a}$ and $4 \mathrm{~b}$ at $60{ }^{\circ} \mathrm{C}$, it is clearly observed that AP conversion on Pd@Ph-POP was $60 \%$ after 5 min and reached $100 \%$ within 20 minute, whereas in the case of $\mathrm{Pd} @ \mathrm{Al}_{2} \mathrm{O}_{3}$ we attained $61 \%$ of conversion. The catalytic reaction was accompanied by a continuous increase in $\mathrm{PhE}$ selectivity (42\%) along with EB (18\%) after an initial 5 min, suggesting that the first step is associated with the hydrogenation of AP to PhE. However, with the gradual advancement of the reaction we have achieved an increased selectivity to EB after $60 \mathrm{~min}$ at full conversion (Figure 4a). Surprisingly, on the other hand for $\mathrm{Pd} @ \mathrm{Al}_{2} \mathrm{O}_{3}$ the selectivity towards $\mathrm{PhE}$ was $27 \%$ after the initial $5 \mathrm{~min}$ and no prominent peak for EB was visible after $60 \mathrm{~min}$ (Figure 4b). Therefore, we consider that Pd@Ph-POP exhibited superior catalytic performance in the hydrogenation of AP, providing high conversion (100\%) and selectivity (100\%) to EB, and exhibiting a turnover frequency (TOF) of $5.42 \mathrm{~min}^{-1}$. On $\mathrm{Pd} @ \mathrm{Al}_{2} \mathrm{O}_{3}$, we achieved 75\% AP conversion and 3\% selectivity to $\mathrm{EB}$ after $60 \mathrm{~min}$ reaction time and TOF was $3.80 \mathrm{~min}^{-1}$. The higher TOF of Pd@Ph-POP could be assigned to the higher oxygen content, which helps in homogeneous dispersion of Pd nanoparticles and presence of electron-rich Pd formed through the strong electronic interaction between $\mathrm{Pd}$ and $\mathrm{O}$ atoms in the polymer framework which had been confirmed from comparison of XPS analysis of bare Ph-POP and Pd@Ph-POP (Figure S13, SI), ${ }^{14}$ facilitating hydrogenation over the electron-enriched metallic Pd. ${ }^{13}$ The superior selectivity towards EB of Pd@Ph-POP (100\%) than Pd@ $\mathrm{Al}_{2} \mathrm{O}_{3}(3 \%)$ under similar reaction conditions could correspond to the strong effect of the hydroxyl rich polymer support acidity promoting dehydration route of $\mathrm{PhE}$ to $\mathrm{EB}$ transformation, as evidenced from higher surface acid strength of Ph-POP $(1.603 \mathrm{mmol} / \mathrm{g})$ compared to alumina $(0.936 \mathrm{mmol} / \mathrm{g})$ determined from $\mathrm{NH}_{3}$-TPD measurement which is in good agreement with the work reported by Chen et al. ${ }^{12}$ 

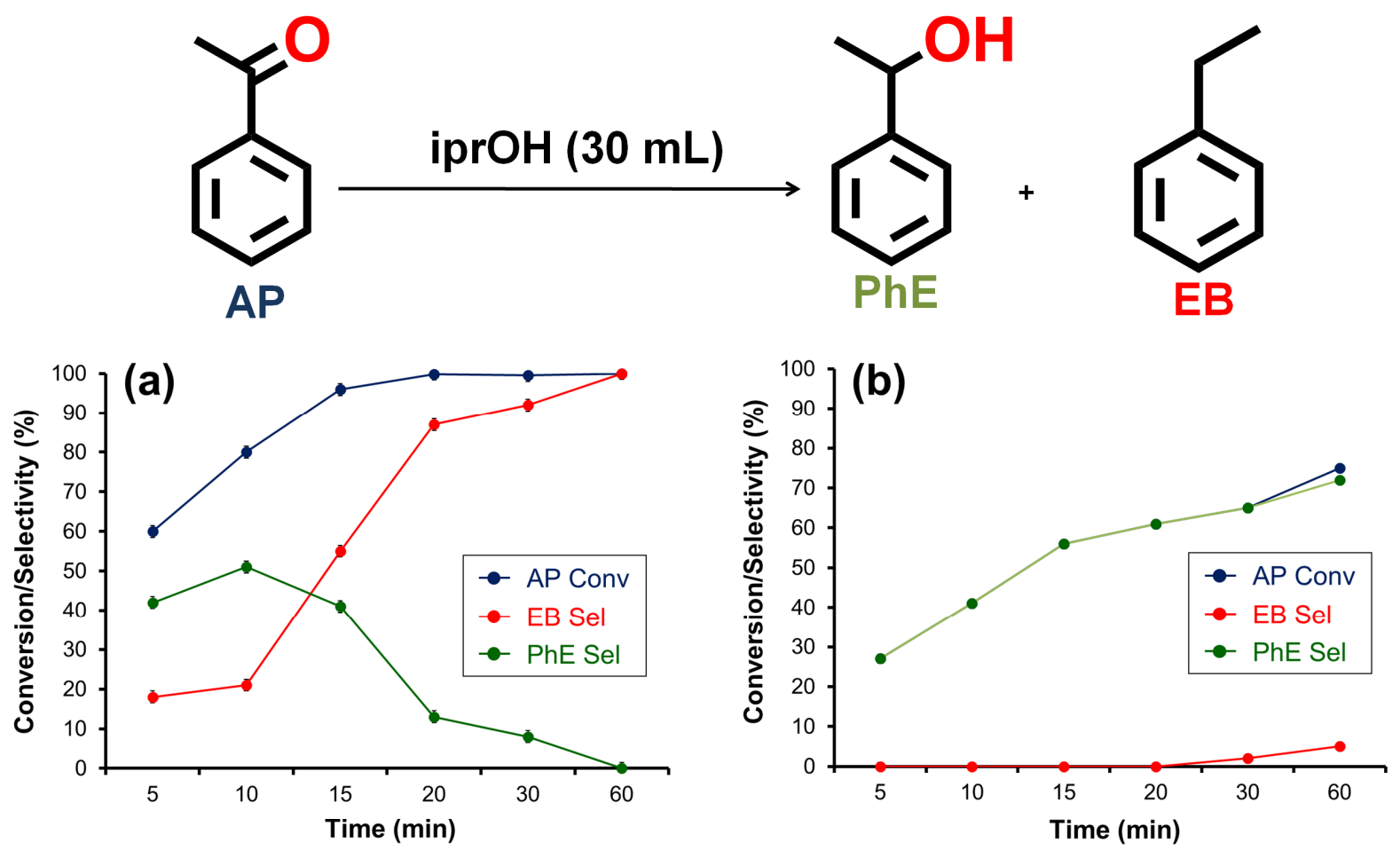

(c)

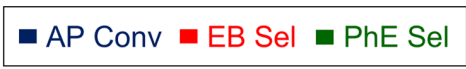

(d)
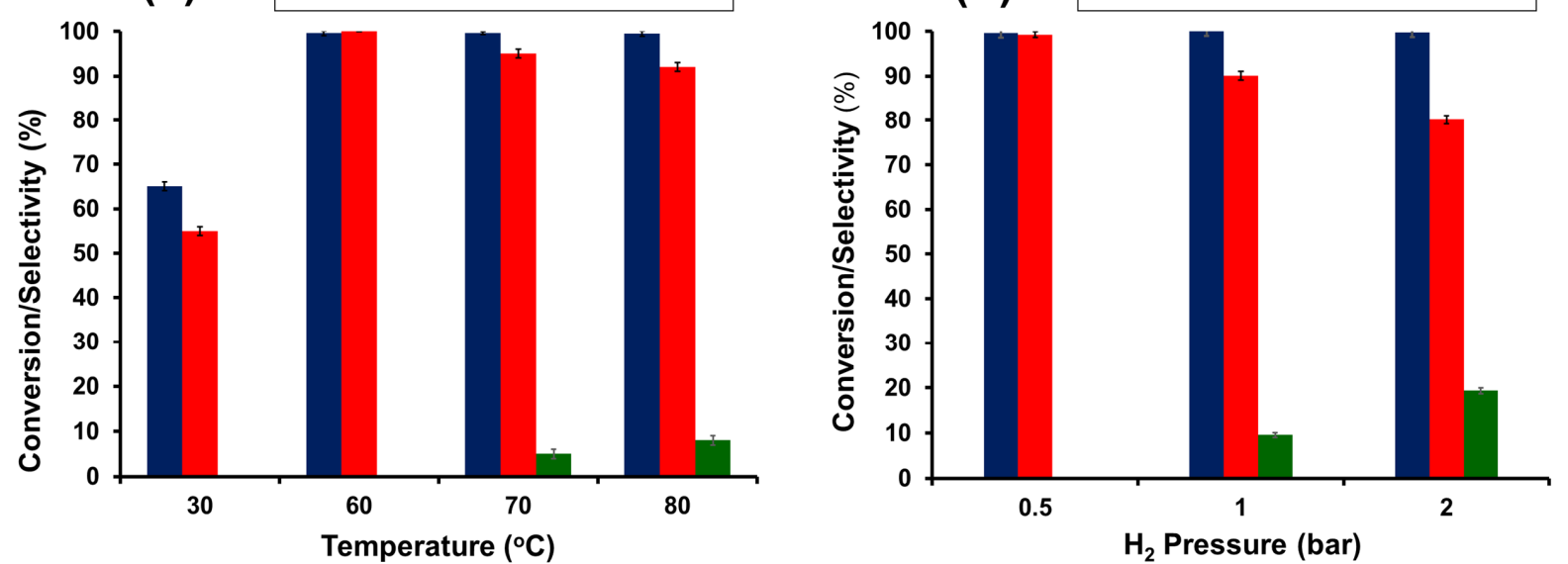

Figure 4: Evaluation of reactant and product distribution with respect to time over $\mathrm{Pd} @ \mathrm{Ph}$ POP (a) and Pd@ $\mathrm{Al}_{2} \mathrm{O}_{3}$ (b); Effect of temperature (c) and $\mathrm{H}_{2}$ pressure (d) of Pd@Ph-POP for acetophenone hydrogenation. Reaction conditions: Acetophenone $(120 \mathrm{mg}, 1 \mathrm{mmol})$, isopropanol $(30 \mathrm{~mL}), 0.5$ bar $\mathrm{H}_{2}$ pressure, temperature of $60^{\circ} \mathrm{C}$, Catalyst $(15 \mathrm{mg})$.

The crucial role of reaction temperature in AP hydrogenation has been thoroughly examined over our catalyst $\mathrm{Pd} @ \mathrm{Ph}-\mathrm{POP}$ in temperature range $30{ }^{\circ} \mathrm{C}$ to $80{ }^{\circ} \mathrm{C}$ under 0.5 bar pressure which is shown in Figure 4c. From the profile it has been clearly interpreted that with upraising temperature catalytic activity increases with a high AP conversion and EB selectivity above $30{ }^{\circ} \mathrm{C}$, indicating much faster reaction kinetics. But a gradual drop in EB selectivity was observed at above $60{ }^{\circ} \mathrm{C}$ which could be assigned to appearance of ethylcyclohexane (EC) as side product triggered by the over hydrogenation of the benzene ring (Figure S14). We have also checked the significant role of hydrogen pressure over Pd@Ph-POP in 
the reaction varying from 0.5 bar to 2 bar pressure (Figure $4 \mathrm{~d}$ ). With increasing hydrogen pressure above 0.5 bar selectivity towards EB has decreased due to formation of ethylcyclohexane (EC) through over-hydrogenation owing to the availability of a high concentration of hydrogen. Figure S15 (SI) revealed that isopropanol has been preferred as the best solvent among all the solvents screened as explained based on hydrogen-bond-acceptance ability (HBA) $(\beta)$ values in Table S2, SI. In order to evaluate the superiority nature of Pd@Ph-POP, we have compared the catalytic activity with the $\mathrm{Al}_{2} \mathrm{O}_{3}$ and carbon supported Pd-NPs and bare Pd-NPs (Figure S16, SI) under optimized reaction condition. The poor activity of unsupported Pd-NPs (AP conversion only 34\%) was due to aggregation of nanoparticle during reaction and having no change in electronic properties of Pd-NPs compared to supported Pd catalyst. ${ }^{41}$ The higher activity of $\mathrm{Pd} @ \mathrm{Al}_{2} \mathrm{O}_{3}$ compared to $\mathrm{Pd} @ \mathrm{C}$ could be attributed to higher acidic nature of $\mathrm{Al}_{2} \mathrm{O}_{3}$ than carbon which is crucial factor for acetophenone hydrogenation reaction. ${ }^{42}$ The highest activity of Pd@Ph-POP may be explained through changes in electronic properties of $\mathrm{Pd}$ through electron donation from highly oxygen enriched Ph-POP framework and higher acidic nature of Ph-POP than $\mathrm{Al}_{2} \mathrm{O}_{3}$ which are supported by XPS studies and $\mathrm{NH}_{3}$-TPD analysis, respectively. In addition, the Ph-POP framework is less prone to coordinate organic molecule than its $\mathrm{Al}_{2} \mathrm{O}_{3}$ counterpart which contributes in higher catalytic activity, is in good agreement with the DFT calculations and is also established from ATR-IR study which have been thoroughly discussed later.

\section{3. in situ ATR-IR investigation.}

AP hydrogenation on Pd@Ph-POP and $\mathrm{Pd} @ \mathrm{Al}_{2} \mathrm{O}_{3}$ was studied by concentration modulated excitation ATR-IR spectroscopy under similar conditions to those used for the catalytic experiments of Figure 4. The phase-resolved spectra of Figure 5 obtained after phase sensitive detection ${ }^{19}$ provide mechanistic details. The spectra show a signal at $1237 \mathrm{~cm}^{-1}$ that exhibits opposite sign to those at 1828 and $1758 \mathrm{~cm}^{-1}$. The different signs suggest that the species characterized by the signal at $1237 \mathrm{~cm}^{-1}$ and by the latter two signals convert into each other. Identical experiments in cyclohexane solvent (not shown here) demonstrate that these signals appear only in isopropanol solvent. Therefore, we take them as evidence for the occurrence of transfer hydrogenation reaction, i.e. isopropanol $\left(1828\right.$ and $\left.1758 \mathrm{~cm}^{-1}\right)$ transforming into acetone $\left(1237 \mathrm{~cm}^{-1}, v(\mathrm{C}-\mathrm{C})\right)^{43}$ upon repeated introduction of AP into the ATR-IR cell. The signals are larger (by a factor ca. 2.25) in the case of $\mathrm{Pd} @ \mathrm{Al}_{2} \mathrm{O}_{3}$ suggesting that on this catalyst the transfer hydrogenation occurs more easily, probably as a result of the $\mathrm{H}$ exchange between the solvent and AP to produce acetone and $\mathrm{PhE}$, the major product observed for 
$\mathrm{Pd} @ \mathrm{Al}_{2} \mathrm{O}_{3}$ (Figure 5b). Signals at 1690, 1680, 1600, 1582, 1449, 1355 and $1268 \mathrm{~cm}^{-1}$ belong to $\mathrm{AP}$, as indicated by the corresponding experiment in the absence of any catalyst. This latter experiment also demonstrates the need of the presence of a catalyst to observe the signals attributed to consumption of isopropanol and formation of acetone, thus confirming their assignment to the occurrence of the transfer hydrogenation reaction. In this regard, Alonso et $a l$. also reported the similar type of transfer of hydrogen atom from isopropanol to acetophenone on Ni-based catalyst using deuterium-labelled isopropanol. ${ }^{44}$ However, due to the complications arising from the proton exchange between isopropanol/isopropoxide and acetophenone on metal catalysts (also called the dihydride-type mechanism), ${ }^{44-45}$ and the autocatalytic role of hydrogen-originated from secondary alcohol during the hydrogenation of carbonyl compounds on metal catalysts was also reported, ${ }^{46}$ it is not possible to reach a mechanistic conclusion on the role of isopropanol during the hydrogenation of acetophenone. Therefore, the results obtained from the in situ-ATR-IR herein provide another convincing evidence for the occurring of the hydrogen transfer between isopropanol and acetophenone.

Considering that the signal at $1237 \mathrm{~cm}^{-1}$ belongs to acetone, it is then possible that the signals at $1690-1680 \mathrm{~cm}^{-1}$ belong to acetone ${ }^{12}$ as well rather than to AP, or to both. This may be corroborated by the fact that their intensity is much lower when the catalyst layer is present than in the experiment without catalyst, while typically this is not the case in ATR-IR. Moreover, the AP solution displays signals at 1680 and $1268 \mathrm{~cm}^{-1}$ of comparable intensity. On the contrary, the latter is more intense when a catalyst is present, suggesting that a complex envelope contributes to the signals in the region at ca. $1680 \mathrm{~cm}^{-1}$, including the changes of baseline caused by the change of sign between the two signals at 1758 and $1630-1620 \mathrm{~cm}^{-1}$. An additional shoulder at $1710 \mathrm{~cm}^{-1}$ for $\mathrm{Pd@} \mathrm{Al}_{2} \mathrm{O}_{3}$ in Figure $5 \mathrm{~b}$ further contributes to the evidence for the production of acetone.

The width of the signals at $1630 \mathrm{~cm}^{-1}$ (Figure 5a) and $1621 \mathrm{~cm}^{-1}$ (Figure 5b) encourages us to assign them tentatively to the adsorbed carbonyl groups rather than to the $v(C=C)$ mode of styrene previously observed at $1656 \mathrm{~cm}^{-1}$. $^{47}$ The region between 1650 and $1350 \mathrm{~cm}^{-1}$ is very different on the two catalysts, $\mathrm{Pd} @ \mathrm{Al}_{2} \mathrm{O}_{3}$ displaying additional broad signals at 1560, 1463 and $1410 \mathrm{~cm}^{-1}$ indicative of adsorbed species of difficult assignment, possibly on $\mathrm{Al}_{2} \mathrm{O}_{3}$. These signals may be due to the presence of EB. ${ }^{47}$ Both EB and PhE exhibit a signal at 1494 $\mathrm{cm}^{-1}$ that becomes evident only for Pd@Ph-POP (Figure 5a). It could be that due to the short pulses (60 s) of the modulation experiment, $\mathrm{PhE}$ is also produced by $\mathrm{Pd} @ \mathrm{Ph}-\mathrm{POP}$, as indicated by the transient production of $\mathrm{PhE}$ in Figure $4 \mathrm{a}$ with maximum at $10 \mathrm{~min}$. On $\mathrm{Pd} @ \mathrm{Al}_{2} \mathrm{O}_{3}$, signals are much broader indicating that these species are to some extent retained 
by $\mathrm{Al}_{2} \mathrm{O}_{3}$; in contrast, the much weaker but better resolved signal at $1494 \mathrm{~cm}^{-1}$ suggests that this species produced by Pd@Ph-POP is released more easily in solution. This behavior may indicate that $\mathrm{Ph}-\mathrm{POP}$ framework is less prone to coordinate organic residues than $\mathrm{Al}_{2} \mathrm{O}_{3}$.
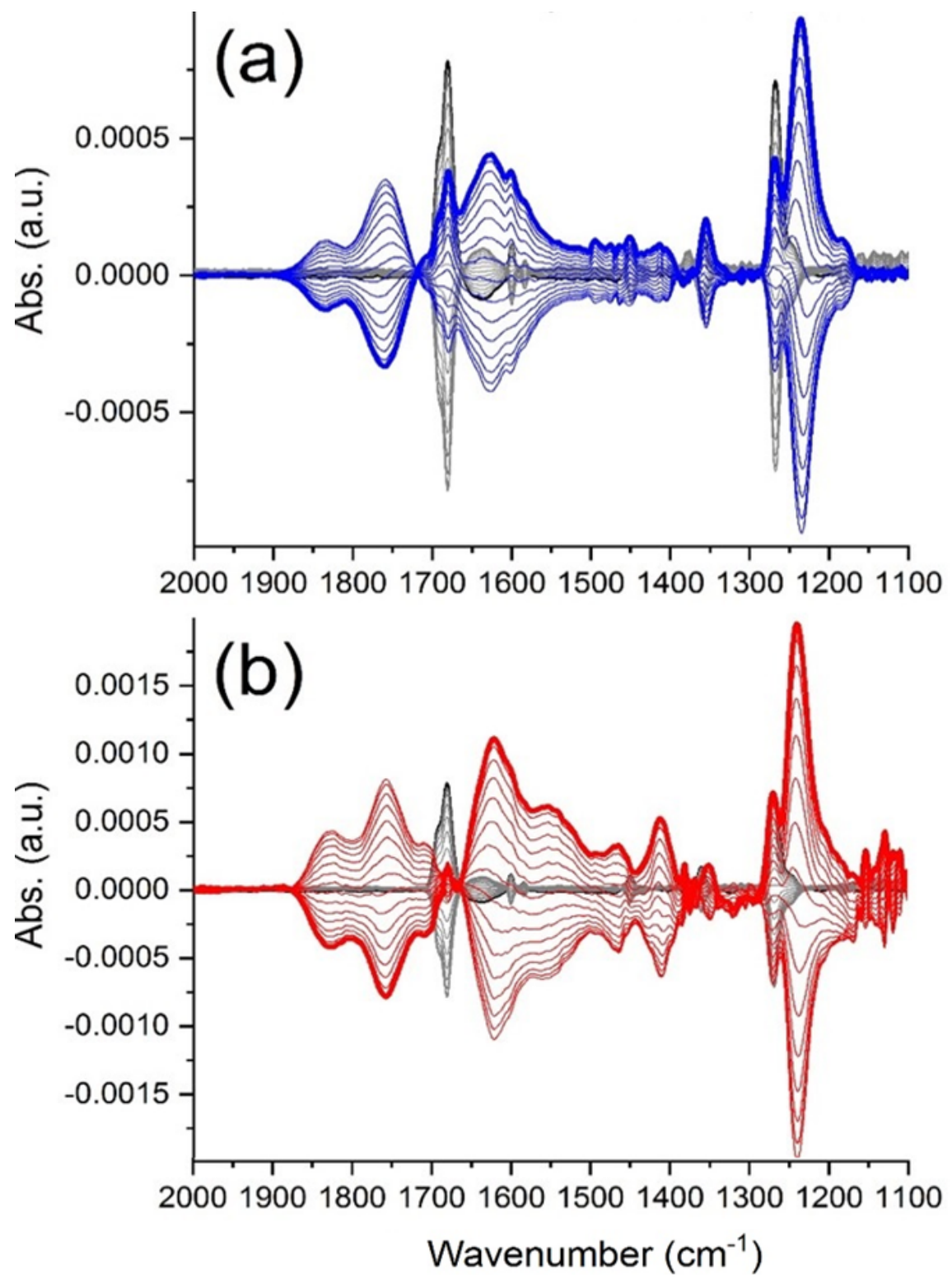

Figure 5: Phase-resolved spectra obtained in modulation ATR-IR experiments consisting in alternate pulses of AP- $\mathrm{H}_{2}$-IPA and $\mathrm{H}_{2}$-IPA on (a) Pd@Ph-POP and (b) $\mathrm{Pd} @ \mathrm{Al}_{2} \mathrm{O}_{3}$ at $60^{\circ} \mathrm{C}$. The grey spectra correspond to an identical modulation experiment in absence of any catalyst and are repeated in both panels. Thick spectra are used to drive the eye

\subsection{Theoretical investigation.}

\subsubsection{Hydrodeoxygenation via direct surface hydrogen $\left(H^{*}\right)$ route}

Density functional theory (DFT) calculations were performed to gain detailed mechanistic understanding for the HDO conversion of acetophenone (AP) on the fabricated Pd@Ph-POP catalyst in this study. Firstly, we investigated the detailed mechanism of HDO conversion facilitated by surface hydrogen $\left(\mathrm{H}^{*}\right)$ of $\mathrm{AP}$ to $\mathrm{EB}$ on $\mathrm{Pd}(111)$ surface. The overall reaction 
network and energy profile for this transformation is presented in Figure 6, while the structures of key intermediates and transition states are shown in Figure 7.

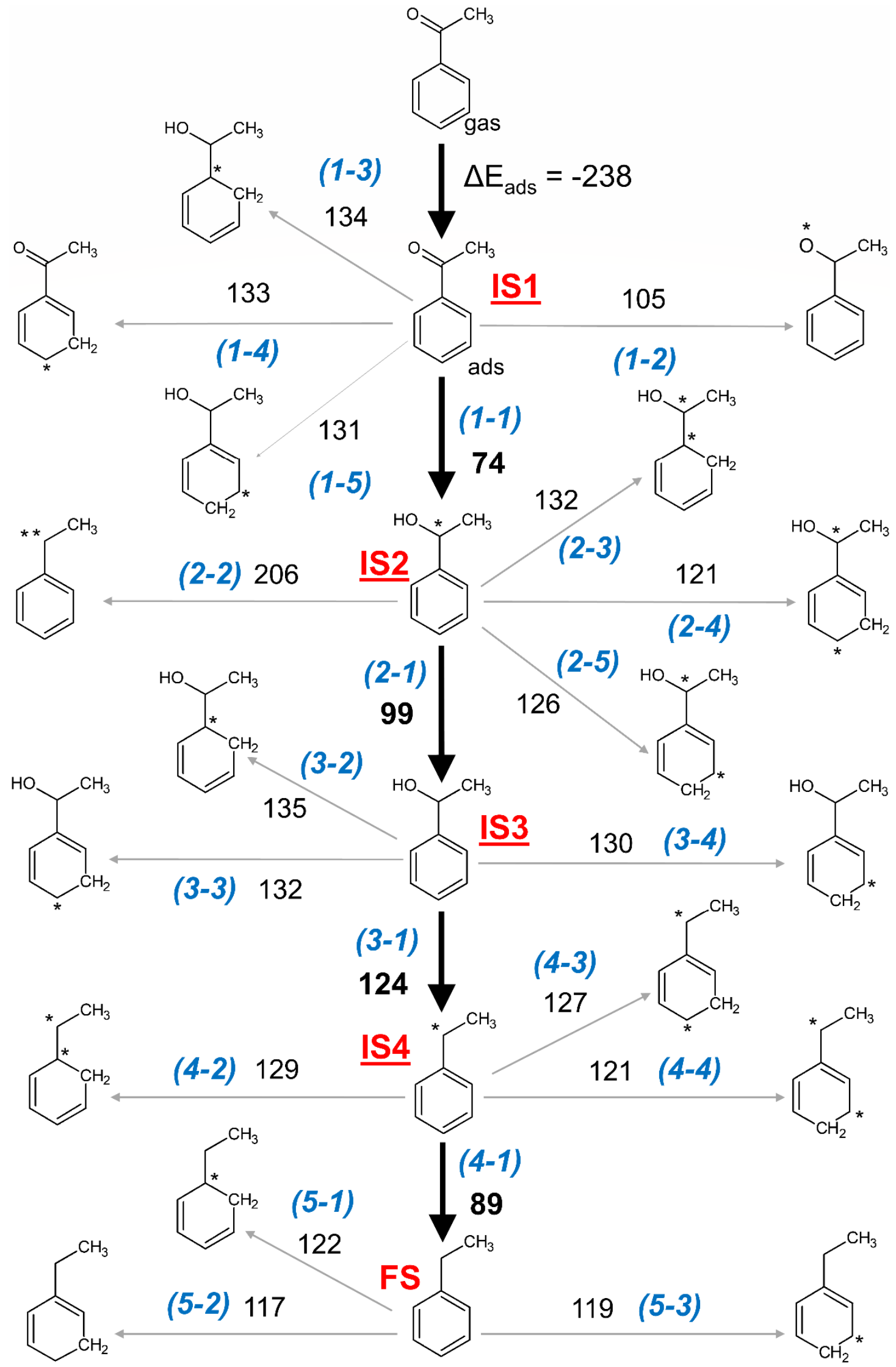


Figure 6: Energy profile for HDO conversion of acetophenone to Ethyl Benzene on $\mathrm{Pd}(111)$, facilitated by surface hydrogen atoms. Activation barriers (black, regular) $(\mathrm{kJ} / \mathrm{mol})$ and index (blue, italic) of the reactions are inserted. Bold arrows show the most feasible reaction pathway. (IS = Intermediate state, FS = Final state)

The conversion of AP on Pd(111) surface starts by the adsorption of AP on the terrace site of $\mathrm{Pd}(111)$ with strong adsorption energy of $-238 \mathrm{~kJ} / \mathrm{mol}$ (Figure 6). In the most stable adsorption configuration, AP coordinates to the $\mathrm{Pd}$ surface via both the $\mathrm{C}=\mathrm{O}$ group and the benzene ring as shown in IS1, Figure 7a. This type of strong interaction was reported as the result of the concerted effect of covalency and vdW bonding between aromatic compounds and transition metal surfaces. ${ }^{22-23}$ Experimental adsorption energy for benzene and phenol adsorption on Pd(111) surface was reported as -197 and $-193 \mathrm{~kJ} / \mathrm{mol}^{23,48}$ respectively, demonstrating the strong binding of the benzene ring on Pd. Under the hydrogen feed as applied in our experimental conditions, $\mathrm{H}_{2}$ gas could be dissociated on $\mathrm{Pd}(111)$ surface with the very low barrier, ${ }^{49}$ forming surface hydrogen atoms which subsequently could act as strong hydrogenation agents to process the HDO conversion of AP. ${ }^{27,13,50}$ The most feasible initial hydrogenation of AP facilitated by this surface hydrogen route occurs at the oxygen atom of the acetyl $\mathrm{C}=\mathrm{O}$ group with the activation barrier of $74 \mathrm{~kJ} / \mathrm{mol}$ (Figure 6 and TS1-1 in Figure $7 \mathrm{f}$ ), forming the hydroxyl group in the intermediate IS2 (Figure 7b). This value is consistent with the reported barrier of $78 \mathrm{~kJ} / \mathrm{mol}$ for hydrogenation to oxygen atom of glucose carbonyl group on $\operatorname{Pd}(111)$ surface. $^{25}$ Other initial hydrogenation pathways of AP on Pd(111) surface all have significantly higher activation barriers and therefore more difficult. Indeed, the hydrogenation into carbon atom of the acetyl $\mathrm{C}=\mathrm{O}$ group has the activation barrier of $105 \mathrm{~kJ} / \mathrm{mol}$ (TS12, Figure 7g). Hydrogenations to different $\mathrm{C}$ atoms of the aromatic ring, either to the ortho-, para- or meta- positions all have similar activation barriers around $131 \mathrm{~kJ} / \mathrm{mol}$ (Figure 6) and are the most difficult routes among the initial hydrogenations of AP on Pd surface. The transition state of hydrogenation to $\mathrm{C}$ atom at the para-position of aromatic ring (TS1-5) is shown in Figure $7 \mathrm{~h}$ and hydrogenation to $\mathrm{C}$ atom at other positions of aromatic ring are presented in the SI.

The most feasible $2^{\text {nd }}$ step of the process is the hydrogenation to carbon atom of the intermediate IS2, forming phenylethanol ( $\mathrm{PhE}$ ) (IS3, Figure 7c). This step has the activation barrier of $99 \mathrm{~kJ} / \mathrm{mol}$ (Figure 6 and TS2-1, Figure 7i), and is lower than the barriers of hydrogenation to carbon atoms of the aromatic ring (Figure 6 and SI). From the theory of rate constant, this value of activation barrier is still feasible at our reaction temperature (e.g. $60^{\circ} \mathrm{C}$ ) ${ }^{51}$ The dissociation of $\mathrm{C}-\mathrm{OH}$ bond in the intermediate IS2 (dehydroxylation reaction) is very difficult due to extremely high activation barrier of $206 \mathrm{~kJ} / \mathrm{mol}$ (TS2-2, Figure 7j) and therefore could 
not be processed at our experimental conditions. From the data observed, it could be seen that the direct hydrogenation of AP to $\mathrm{PhE}$ by surface hydrogen atoms on Pd catalyst is feasible, and is consistent with the high selectivity and dominated formation of $\mathrm{PhE}$ in the initial process of AP hydrogenation as shown in Figure 4 on both $\mathrm{Pd} @ \mathrm{Al}_{2} \mathrm{O}_{3}$ and Pd@Ph-POP catalysts. 

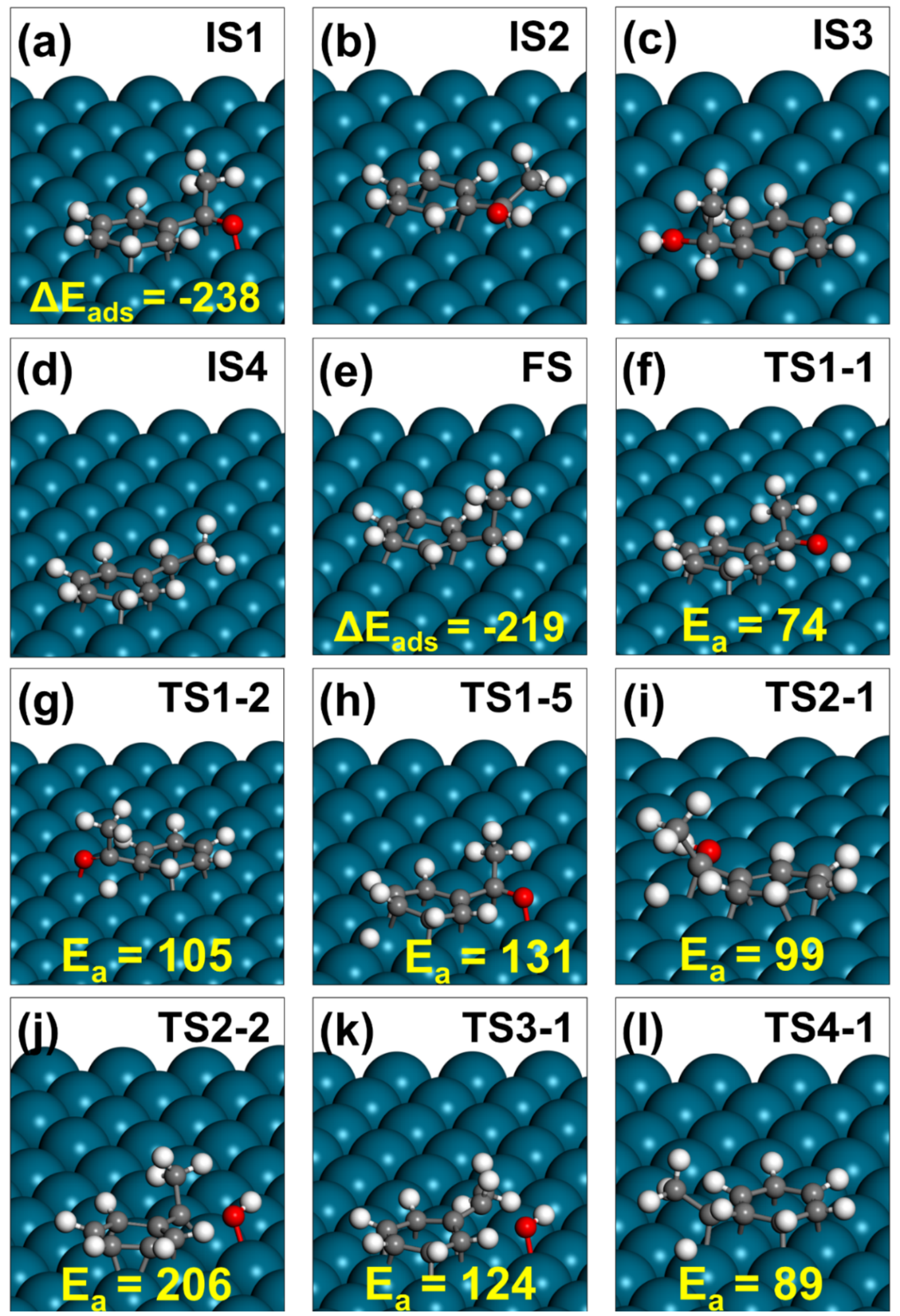

Figure 7: Structure of the Intermediates and Transitions states of reactions during the HDO conversion of acetophenone on $\operatorname{Pd}(111)$ surface. (a) adsorption of acetophenone, IS1; (b) 
product of first hydrogenation to formyl-O atom, IS2; (c) Intermediate phenyl-ethanol (PhE), IS3; (d) product of dehydroxylation step from PhE, IS4; (e) final product Ethyl Benzene (EB), FS; Transition state for reactions in the initial step: (f) hydrogenation to formyl-O atom, TS1-1; (g) hydrogenation to formyl-C atom, TS1-2; (h) hydrogenation to aromatic ring; Transition state for reactions in the second step: (i) hydrogenation to $\mathrm{C}$ atom, forming $\mathrm{PhE}$, TS2-1; (h) dehydroxylation, TS2-2; Transition state for (j) dehydroxylation from PhE in the third step, TS3-1 and for (l) hydrogenation in the fourth step, forming Ethyl benzene, TS4-1. Color code: small grey, white and red balls represent carbon (C), hydrogen $(\mathrm{H})$ and oxygen $(\mathrm{O})$ atoms, respectively, while big blue balls represnt surface palladium $(\mathrm{Pd})$ atoms.

After $\mathrm{PhE}$ is formed, it could be continuously processed either via the dehydroxylation reaction (deoxygenation route) forming the precursor for ethylbenzene (EB) formation (IS4, Figure $7 d$ ) or via the further hydrogenation to carbon atoms in the aromatic ring (Figure 6). Our DFT calculations show that the former route (dehydroxylation) is slightly more favourable with the activation barrier of $124 \mathrm{~kJ} / \mathrm{mol}$ (TS3-1, Figure $7 \mathrm{k}$ ), while the activation barrier of the later route (hydrogenation of aromatic ring) is higher than $130 \mathrm{~kJ} / \mathrm{mol}$ (Figure 6 and SI). Despite of that, those activation barriers for both routes are considered quite high and therefore hinder those reactions at our operational conditions. ${ }^{51}$ However, if the dehydroxylation could be processed, the subsequent hydrogenation of the intermediate IS4 is much more feasible with the barrier of $89 \mathrm{~kJ} / \mathrm{mol}$ (TS4-1, Figure 7l), generating the final product EB as shown in Figure 6 and Figure 7e (FS). Once EB is formed, carbon atoms of the aromatic ring could be over-hydrogenated with activation barriers in the range of $117-122 \mathrm{~kJ} / \mathrm{mol}$ forming the side product ethylcyclohexane (EC) (Figure 6 and SI). Note that the activation barrier of this step is also considered high and therefore require certain high temperature or high level of hydrogen pressure to facilitate those reactions, explaining the increase of selectivity towards EC at higher temperature or higher $\mathrm{H}_{2}$ pressure as shown in Figure 4c,d. From the overall reaction network, it could be seen that the rate determining step for the HDO conversion of $\mathrm{AP}$ to $\mathrm{EB}$ is the dehydroxylation of $\mathrm{PhE}$, and the high barrier of this step explain why the yield of EB formation on conventional $\mathrm{Pd} @ \mathrm{Al}_{2} \mathrm{O}_{3}$ catalyst is low as shown in Figure 4b.

\subsubsection{Role of Ph-POP frame structure in facilitating the formation of ethylbenzne (EB).}

Instead of the direct dehydroxylation pathway on surface Pd atoms as presented in Figure 6 and Figure 7k, there is an alternative pathway to facilitate this step by the hydrogenshuttling mechanism. In this pathway, water molecule acts as a hydrogen shuttle to transfer the adsorbed surface $\mathrm{H}$ atom on $\mathrm{Pd}(111)$ surface to the $\mathrm{OH}$ group of phenylethanol and facilitating the dehydration, forming $\mathrm{H}_{2} \mathrm{O}$, as shown in Figure 8. The activation barrier for this 
reaction is $87 \mathrm{~kJ} / \mathrm{mol}$, lower than the direct dehydroxylation in Figure $7 \mathrm{k}$. In the initial state, water is located in the vicinity of the adsorbed phenylethanol and surface $\mathrm{H}$ atom on Pd surface. In the transition state, one $\mathrm{H}$ atom of water molecule is transferred to the hydroxyl $\mathrm{OH}$ group of phenylethanol facilitating the dehydroxylation, while the surface $\mathrm{H}$ adsorbed in $\mathrm{Pd}$ surface is transferred to the water molecule simultaneously in the concerted mechanism. This type of water mediated $\mathrm{H}$-shuttling mechanism has also been reported in literature for the water-assisted dehydroxylation from $\mathrm{HCOH}$ on $\mathrm{Ru}$ catalyst, ${ }^{52} \mathrm{CO}$ hydrogenation of adsorbed $\mathrm{CO}$ on $\mathrm{Co}(111)$ surface, ${ }^{53}$ formyl $\mathrm{C}-\mathrm{H}$ dissociation from glucose on $\mathrm{CuO}$ catalyst ${ }^{54}$ and dehydroxylation of carboxylic acids on $\operatorname{Pd}(111)$ surface. ${ }^{27}$ It is important to mention that this type of H-shuttling reaction usually suffer from extra entropic energy penalty for locating the water molecule to the exact position in the transition state (computed to be $\sim 55.4 \mathrm{~kJ} / \mathrm{mol}$ at reaction temperature of $60{ }^{\circ} \mathrm{C}$ in this study), as was also reported by Gunasooriya et al. ${ }^{53}$ and Amaniampong et al. ${ }^{55}$ This entropic penalty therefore increases the total barrier for the $\mathrm{H}$ shuttling reaction to $\sim 142 \mathrm{~kJ} / \mathrm{mol}$, making it further less favourable compare to the direct dehydroxylation pathway (124 kJ/mol, Figure 6 \& 7k). However, when Pd-NPs are anchored on the Ph-POP frame structure, the presence of hydroxyl groups in Phenol monomers stabilize the water near the surface by $\sim 50.1 \mathrm{~kJ} / \mathrm{mol}$ as was reported by calorimetric measurement in Campbell et al. ${ }^{56}$ and our computational calculation in this study also show the binding energy of water on $\mathrm{Pd}(111)$ surface with pre-adsorbed phenol is $\sim 70 \mathrm{~kJ} / \mathrm{mol}$ (Figure S25, SI). This enhancement in the affinity of water molecule nearby the surface therefore is able to compensate the entropic energy penalty for this reaction, making it now becomes much more feasible at the reaction conditions.

\section{Initial state}

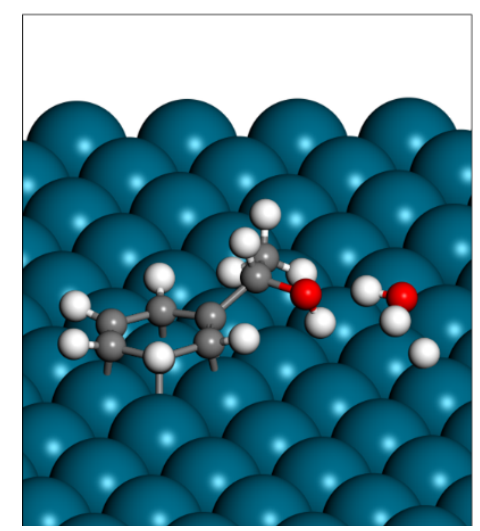

\section{Transition state}

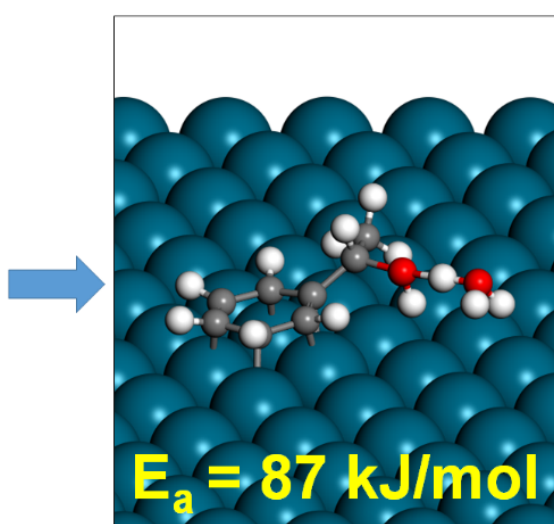

Final state

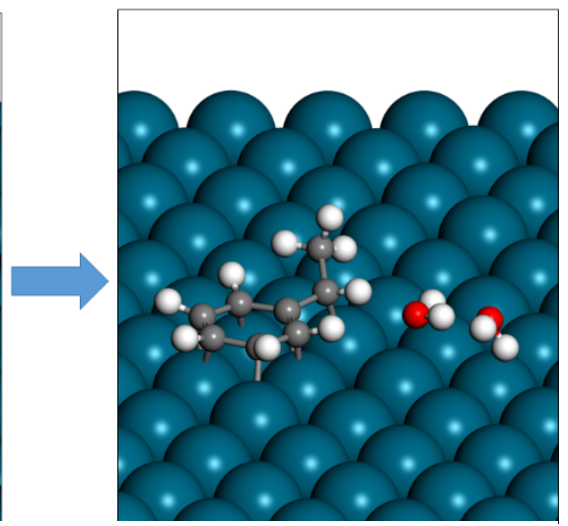

Figure 8: Initial state, Transition state, and Final state for the dehydroxylation of phenyl ethanol on Pd(111) surface via the Hydrogen-shuttling mechanism. Color code is the same as in Figure 7. 
Besides, the strong coordination of Pd-NPs with Phenol fragments (from the Ph-POP structure) also results in lowering the binding energy of ethyl benzene on $\operatorname{Pd}(111)$ surface. The adsorption energy of ethyl benzene on clean $\mathrm{Pd}(111)$ surface is $-219 \mathrm{~kJ} / \mathrm{mol}$ (FS, Figure 7e) but it is reduced to $-181 \mathrm{~kJ} / \mathrm{mol}$ (Figure S25, SI) when Phenol is pre-adsorbed on $\mathrm{Pd}(111)$ surface. The lower binding energy of the aromatic ring to pre-adsorbed Phenol surface therefore makes the hydrogenation to carbon atoms of aromatic ring more difficult and facilitates the desorption of the final product as was reported in earlier studies. ${ }^{39,57}$ This observation is in excellent agreement with the ATR-IR analysis presented in the previous section. Furthermore, the stronger coordination between Pd-NPs with Ph-POP also results in lower coverage of surface $\mathrm{H}^{*}$. Due to the repulsion between the bulky aromatic rings of Ph-POP and surface $\mathrm{H}^{*}$ atoms, the available sites for $\mathrm{H}_{2}$ to adsorb on $\mathrm{Pd} @ \mathrm{Ph}-\mathrm{POP}$ is lower than that on $\mathrm{Pd} @ \mathrm{Al}_{2} \mathrm{O}_{3}$ catalyst, results in decreased hydrogenation rate of the $\mathrm{C}$ atoms in aromatic ring and reduces the over-hydrogenation of EB to ethylcyclohexane, as was reported in Gunasooriya et $a{ }^{58}{ }^{58}$ Therefore, these two factors including the weaker binding of the desired product ethyl benzene and lower coverages of surface $\mathrm{H}^{*}$ atoms correlates with the low selectivity of the by-product ethyl cyclohexane and explains very well the high yield of EB produced during the HDO conversion of AP on Pd@Ph-POP in our study.

\subsubsection{Hydrogenation of AP via keto-enol route.}

In the hydrogenation of ketones, the keto-enol tautomerization could happen and open an alternative pathway for the hydrogenation. Usually the enol form is less stable than the keto form, but in some cases the enol form could be stabilized on the surface of the catalyst. ${ }^{59}$ It is reported that the keto-enol tautomerization could be fast and quasi-equilibrated, ${ }^{59-61}$ and if the activation barriers of hydrogenation to the enol structure becomes significantly lower than the barriers of hydrogenation to the keto structure, this pathway will contribute important role in the overall processes. Using isotope labeling, Vila et al. reported that promoting the enol pathway was essential to achieve the high selectivity towards 1,2-propanediol formation during the acetol hydrogenation over $\mathrm{Cu} / \mathrm{Al}_{2} \mathrm{O}_{3}$ catalysts under hydrogenolysis conditions. ${ }^{62}$ Theoretical-based microkinetic study also predicted that the 1-enol hydrogenation pathway became dominated $(84 \%)$ for acetol hydrogenation on $\mathrm{Cu}(111)$ surface under water-free hydrogenation conditions. ${ }^{60}$ On Pt(111) surface, the enol-pathway was also emphasized to be necessary in facilitating the "remote hydrogenation" of the 2,2,2-trifluoroacetophenone (TFAP) to the corresponding unsaturated alcohol. ${ }^{63}$ Moreover, combining scanning tunneling microscopy (STM), infrared reflection-absorption spectroscopy (IRAS) and molecular beam 
techniques, Schauermann and co-authors have also detected the presence of ketone-enol dimers or even ketone-enol-enol trimers upon the adsorption of acetophenone on $\operatorname{Pt}(111)$ surface, ${ }^{59}$ and the keto-enol tautomerization was stated as a first step in the hydrogenation of acetophenone on Pt catalyst. ${ }^{61}$ Therefore, the hydrogenation of AP via the keto-enol route is also investigated by DFT calculations in this study and the results are shown in Figure S27, Supporting Information.

The most stable adsorbed configuration of AP in the enol-form on $\operatorname{Pd}(111)$ surface is presented in Figure S27a, where enol-AP coordinates to the $\mathrm{Pd}$ surface via both the $\mathrm{C}=\mathrm{C}$ bond and the benzene ring. Interestingly, the adsorption energy of the enol-form, $-232 \mathrm{~kJ} / \mathrm{mol}$ is the almost the same as the keto-form (-238 kJ/mol, Figure $7 \mathrm{a})$, although in the gas phase the enol structure is $50 \mathrm{~kJ} / \mathrm{mol}$ less stable than the keto-form (Figure S29, Supporting Information). Hydrogenation to the $\mathrm{CH}_{2}=$ group $\left(\mathrm{C}_{\beta}\right.$ position) has the barrier of only $86 \mathrm{~kJ} / \mathrm{mol}$ (Figure $\mathrm{S} 27 \mathrm{~b})$, while the hydrogenation to the $\mathrm{OH}-\mathrm{CH}=$ group $\left(\mathrm{C}_{\alpha}\right.$ position $)$ is much more difficult with the high barrier of $124 \mathrm{~kJ} / \mathrm{mol}$ (Figure S27c). Therefore, only the former pathway of the enol-route (hydrogenation to the $\mathrm{C}_{\beta}$ position of hydroxyl allyl $\mathrm{OH}-\mathrm{CH}=\mathrm{CH}_{2}$ group) is feasible under our reaction conditions. It is also very consistent with the statement in the study of Attia et al., ${ }^{61}$ which concludes that the hydrogenation of AP on $\mathrm{Pt}(111)$ surface could feasibly occur either to the allyl $\mathrm{C}=\mathrm{C}$ bond of the enol part, or to the carbonyl $\mathrm{C}=\mathrm{O}$ bond of the ketone part of AP. It should be mentioned that the product of hydrogenation to the $\mathrm{C}_{\beta}$ position of enol-route is the same as the product of $1^{\text {st }}$ step reaction during the hydrogenation of the ketoform (hydrogenation to oxygen of carbonyl group, IS2 in Figure 7b). Therefore, although the first step of enol-route is feasible, the subsequent reaction steps of the enol-route are the same as the keto-route and do not change the overall mechanism.

\subsubsection{Hydrogenation of AP via hydrogen transfer route and the role of isopropanol.}

Besides the enol-route, the catalytic hydrogen transfer pathway has also observed for the hydrogenation of carbonyl compounds such as acetophenone and furfural on $\mathrm{Pd},{ }^{64} \mathrm{Ni}^{44-45}$ and $\mathrm{Cu}^{46,64-65}$ catalysts. In this pathway, isopropanol is popularly used as a sacrificial alcohol and a hydrogen donor resource for the hydrogenation. The transfer hydrogenation is an emerging concept in heterogeneous catalysis as a green and cost-effective method to avoid the economical and sustainable challenges of using molecular hydrogen. Furthermore, it was reported that the catalytic hydrogen transfer could increase the activity of catalyst and might have some benefit in changing the the selectivity in the hydrogenation of aromatic and unsaturated ketones and aldehydes. Since isopropanol was used as solvent in our reaction setup 
and the in-situ ATR-IR analysis has detected the hydrogen transfer occurring in the initial process of AP conversion, the activation of AP via the hydrogen transfer pathway on $\mathrm{Pd}(111)$ surface is also evaluated and the results are illustrated in Figure 9 and Figure S28, SI.

First, we evaluated the hydrogen transfer between AP and isopropanol in the liquid phase without the presence of Pd catalyst. Figure S30, SI presents potential energy surfaces (PES) of $\mathrm{H}$-atom transfer reactions between acetophenone (AP) and isopropanol in aqueous phase. Generally, the HAT reactions between AP and isopropanol in aqueous phase are initiated via two pathways (i.e. pathways A and B, Figure S30). The first one is the two-steps reaction pathway and is initiated by a transfer of two H-atoms from isopropanol to AP which is characterized by the activation barrier of $225 \mathrm{~kJ} / \mathrm{mol}$ (TS1A, Figure S30). The second reaction route consists a one-step reaction pathway (pathway B, Figure S30) which is in competition with the first one with the activation barrier being $234 \mathrm{~kJ} / \mathrm{mol}$. This reaction is also occurred by the simultaneous transfer of two Hydrogen atoms from $\mathrm{C}_{2}$ Carbon atom and Hydroxyl $\mathrm{OH}$ group of isopropanol to Oxygen atom of Acetyl $\mathrm{C}=\mathrm{O}$ group and $\mathrm{C}_{1}$ Carbon of $\mathrm{AP}$ (TS1B, Figure S30), respectively. It could be observed that the extremely high barriers of the hydrogen transfer reactions without the presence of Pd catalyst make them could not be processed, in consistent with the claim from ATR-IR data above.
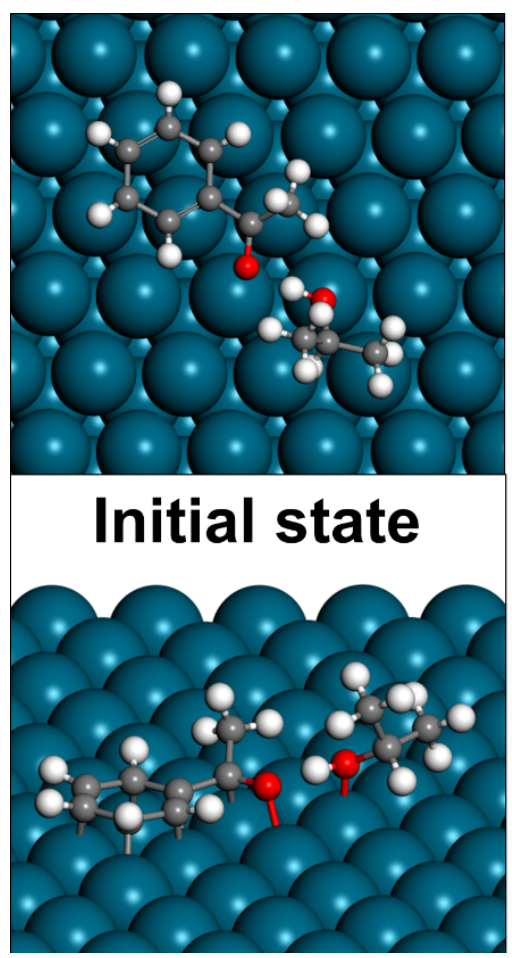

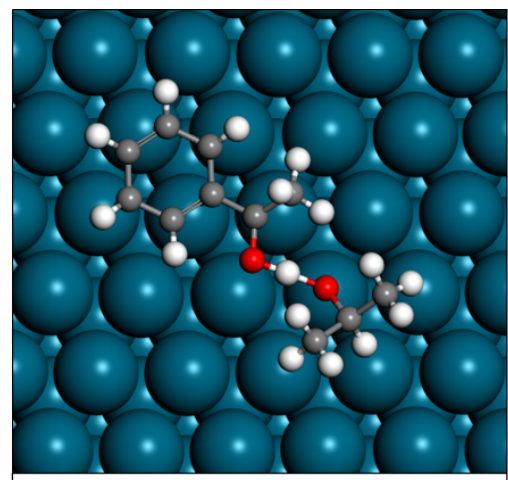

Transition state

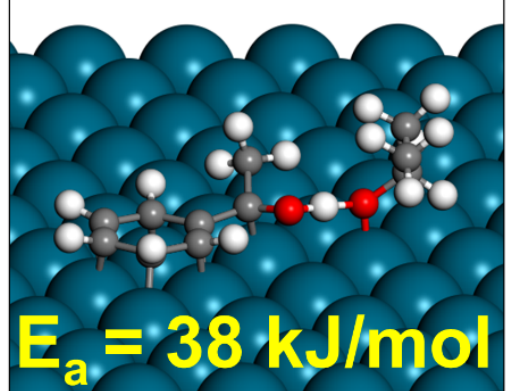

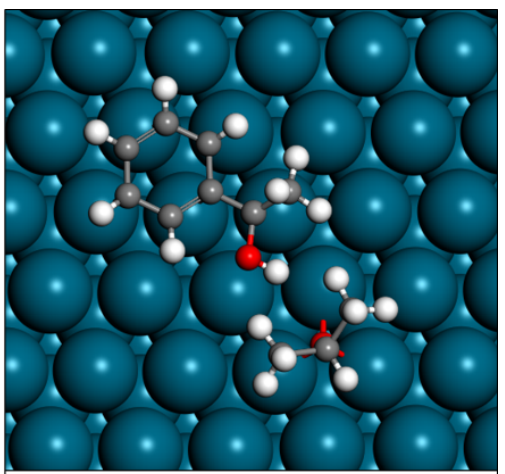

Final state

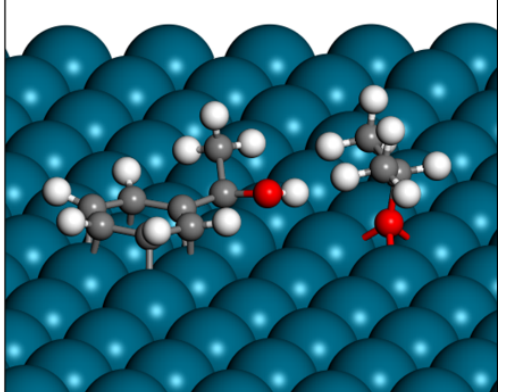

Figure 9: Top view and side view of Initial state, Transition state and Final state for the activation of acetophenone via hydrogen transfer with isopropanol on $\mathrm{Pd}(111)$ surface. Color code is the same as in Figure 7. 
However, on Pd catalyst, the hydrogen transfer from isopropanol-OH group to carbonyloxygen of AP is much more feasible with the low barrier of $38 \mathrm{~kJ} / \mathrm{mol}$ (Figure 9). This barrier is significantly lower than the barrier of $74 \mathrm{~kJ} / \mathrm{mol}$ for the direct hydrogenation by surface hydrogen atoms as presented in Figure $7 \mathrm{f}$, demonstrating the promotion role of hydrogen transfer pathway in activation carbonyl group on the catalysts as reported in literature. ${ }^{44-46,64-}$ ${ }^{65}$ In the initial state, AP and isopropanol co-adsorb on the surface and there is a hydrogen bonding between the carbonyl $\mathrm{C}=\mathrm{O}$ group of $\mathrm{AP}$ and the $\mathrm{OH}$ group of isopropanol with an interaction energy of $15 \mathrm{~kJ} / \mathrm{mol}$ (references to the separately adsorption state of AP and isopropanol on $\operatorname{Pd}(111)$ surface). It is consistent with the experimental observation for the hydrogen bonding interaction between AP-isopropanol on Ni catalyst reported by Bertero et $a l .{ }^{66}$ However, the hydrogen only could be transferred between oxygen atoms. The reactions in which the hydrogen atom is transferred from $\mathrm{OH}$ group of isopropanol to $\mathrm{C}$ atom of the carbonyl in AP or to the hydroxy-alkyl intermediate IS2, and the transfer of hydrogen from $\mathrm{CH}$ group of isopropoxy (product of isopropanol deprotonation) to $\mathrm{O}$ atom of AP carbonyl group are all difficult with barriers higher than $140 \mathrm{~kJ} / \mathrm{mol}$ (Figure S28, SI). The energy profiles for the $\mathrm{HDO}$ conversion of $\mathrm{AP}$ to $\mathrm{EB}$ on $\mathrm{Pd} @ \mathrm{Al}_{2} \mathrm{O}_{3}$ catalyst with and without the presence of isopropanol and on Pd@Ph-POP with the presence of isopropanol are presented in Figure S31, SI.

Therefore, the direct participant of isopropanol via hydrogen transfer route only facilitates the initial hydrogenation step and does not change the subsequent steps, similar to the enol route. But once isopropanol has been deprotonated after the hydrogen transfer, it could be further dehydrogenated with the low barrier of $46 \mathrm{~kJ} / \mathrm{mol}$ (Figure S26, SI) to generate surface hydrogen and produce acetone. All of these observations agree very well with the appearance of signal for acetone upon the introduction of AP to form PhE in the in situ ATR-IR spectra. It should be noted that the applied $\mathrm{H}_{2}$ pressure in our experiment is quite low ( 0.5 bar) to hinder the over-hydrogenation of the aromatic ring, and $\mathrm{H}_{2}$ also need to be dissolved in liquid phase of isopropanol before adsorptive dissociation on $\operatorname{Pd}(111)$ surface to generate surface hydrogen atoms, therefore the coverage of surface hydrogen originated from $\mathrm{H}_{2}$ gas resource might be low and not enough for the HDO process. Therefore, the roles of isopropanol in facilitating the conversion of AP in this study are: i) participating in the hydrogen transfer reaction to hydrogenate the oxygen atom of the carbonyl group with low barrier and ii) supplying surface hydrogen for other hydrogenation reactions. It is also consistent with the coupled "dehydrogenation-hydrogenation mechanism" proposed for this type of hydrogen transfer reaction in literature, ${ }^{46}$ in which the sacrificial alcohol (isopropanol herein) dehydrogenates, 
forming the corresponding ketone (acetone in this case) and surface hydrogen, which is subsequently used to hydrogenate the carbonyl compounds. The higher activity of $\mathrm{Pd} @ \mathrm{Al}_{2} \mathrm{O}_{3}$ than Pd@Ph-POP in the hydrogenation of AP to PhE via the hydrogen transfer pathway in ATR-IR analysis could also be explained due to the coordination of bulky phenol fragments with Pd-NPs in Ph-POP frame structure, resulting in less free sites for isopropanol to interact with AP on Pd surface, finally corresponding to the lower hydrogenation activity towards $\mathrm{PhE}$.

\subsection{Stability testing.}

In order to substantiate the heterogeneity of our newly designed catalyst Pd@Ph-POP we have examined the reusability performances conducting the AP hydrogenation reaction under the applied batch conditions which are shown in Figure S17, SI. After the reaction the catalyst was collected by centrifugation followed by washing with methanol with 4-5 times and dried at $80^{\circ} \mathrm{C}$ for $24 \mathrm{~h}$ and then employed for the next reaction. (Details are given in experimental section). 


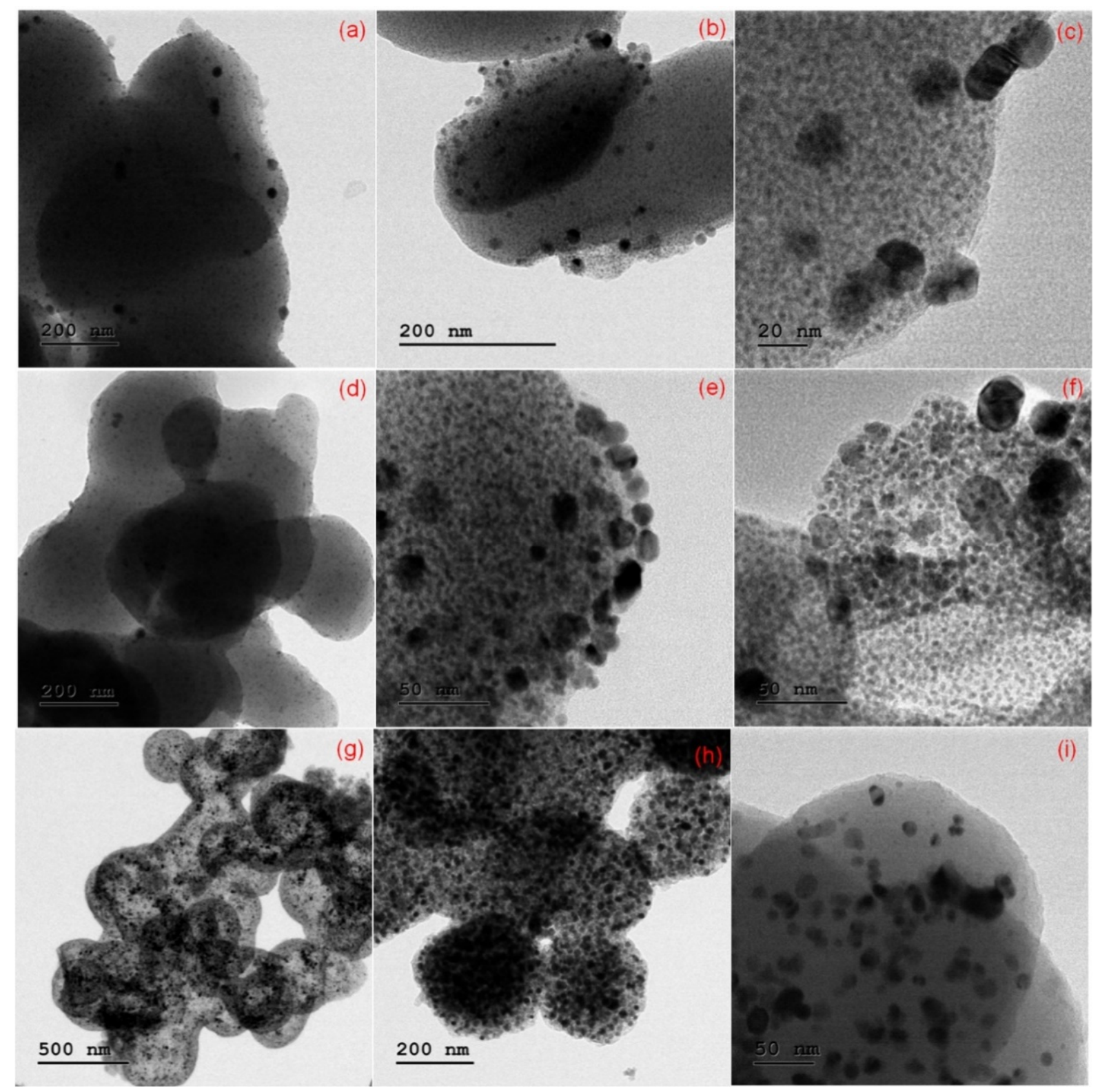

Figure 10: TEM images of reused catalysts after the $3^{\text {rd }}$ cycle $(a, b, c), 6^{\text {th }}$ cycle $(d, e, f)$ and $9^{\text {th }}$ cycle $(\mathrm{g}, \mathrm{h}, \mathrm{i})$.

Pd@Ph-POP represents enormous reusability having consistent conversion of acetophenone with selectivity towards ethyl benzene for at least 10 competitive catalytic cycles under optimized reaction condition. From the Figure S17 (SI), it has been clearly observed that after 9th cycle (i.e. at 10th cycle) only an insignificant drop of acetophenone conversion having $100 \%$ to $92 \%$ with ethylbenzene selectivity from $100 \%$ to $90 \%$ and also after 10 th cycle (i.e. at 11 th cycle) minute change in conversion (from $100 \%$ to $87 \%$ ) and selectivity (from $100 \%$ to $85 \%$ ). This fact could be ascribed to blocking of accessible catalytic active sites because of accumulation of carbonaceous deposits on the catalyst surface or slight confinement of residual reactants and products inside the pores reflected in decrease in surface area of reused 
catalysts (surface area of fresh and reused catalyst are 267 and $243 \mathrm{~m}^{2} \mathrm{~g}^{-1}$, respectively). ${ }^{67,68}$ In addition, the collision of the stirrer and the autoclave wall during the reaction may rupture the exposed surface of $\mathrm{Pd}$, could be one reason behind this reduced product selectivity. ${ }^{15} \mathrm{We}$ have also examined powder XRD, BET and XPS analysis of corresponding spent catalyst which has been shown in Figure S18, SI. There is no change in crystalline phase of $f c c$ Pd (0) and nature of $\mathrm{N}_{2}$-adsorption/desorption isotherm curve of corresponding reused catalyst (Figure S18a, SI) and XRD (Figure S18b, SI), respectively. In this case we have observed BET surface area is $243 \mathrm{~m}^{2} \mathrm{~g}^{-1}$ of reused catalyst. This change in surface area could be ascribed to the accumulation of some carbonaceous products on catalyst surface during the reaction. XPS study (Pd 3d) of reused catalyst (Figure S18c, SI) exhibits two main types of peaks at around 334.9 and $341.2 \mathrm{eV}$, clearly indicates that the chemical state of Pd remain intact after the reaction.

To check the intactness of polymer morphology after the reaction we have performed FESEM analysis of reused catalyst after $3^{\text {rd }}, 6^{\text {th }}$ and $9^{\text {th }}$ cycle which is shown in Figure S19, SI. From Figure S19 (SI), we have obviously found that after three cycles $\left(3^{\text {rd }}, 6^{\text {th }}\right.$ and $\left.9^{\text {th }}\right)$ spherical morphology of polymer with smooth surface remains unaltered with no significant size increment. To verify the location, distribution, size and stability of the Pd-NPs of Pd@PhPOP, we have also conducted TEM analysis of reused catalysts after consecutive catalytic reactions (Figure 10) where the Pd nanoparticles are homogeneously distributed on the $\mathrm{Ph}$ POP surface after successive 10 catalytic runs. But, from particle size distribution analysis (Figure S20, SI) it has been clearly observed that after $3^{\text {rd }}$ catalytic cycle particle size having $16-22 \mathrm{~nm}$ have been increased about $10 \%, 6^{\text {th }}$ cycle about $25 \%$ and $9^{\text {th }}$ cycle about $40 \%$, respectively, compared to fresh Pd catalyst. Figure 10a-c revealed that the average particle size of Pd-NPs somewhat enlarged from 6.4 to $17.9 \pm 0.6 \mathrm{~nm}$ after the third catalytic run but of course a homogeneous distribution on the external surface of Ph-POP is visible. In this case, we could be able to notice that Pd-NPs are exposed out (Figure 10c) to the external surface when the size increases with no aggregation. In strong contrast, at the $6^{\text {th }}$ catalytic cycle a cluster island (Figure 10e) with lump of Pd cloud with the enhancement of mean size from 6.5 to $16.2 \pm 0.7 \mathrm{~nm}$ with somewhat uneven distribution is observed. Closer inspection of the TEM image (Figure 10f) demonstrated that many aggregated nanoparticles with irregular shape are randomly connected to each other which intertwined with carbonaceous network. However, at the $10^{\text {th }}$ catalytic run the mean particle dimension appeared to be $15.8 \pm 0.7 \&$ $19.0 \pm 0.5 \mathrm{~nm}$, respectively, with a rigorous aggregation which could be ascribed to scattering of the small palladium NPs as diffused out of the interior cavities and accumulated on the ex- 
ternal surface, in accordance with the work reported by Mondal and co-workers. ${ }^{14}$ In this case the mean dimension of each spherical Ph-POP was measured to be $\sim 280-354 \mathrm{~nm}$ in good agreement with the FE-SEM analysis. ${ }^{13} \mathrm{C}-\mathrm{CP}$ solid-state MAS NMR spectrum (Figure S21, SI) of the used catalyst after $10^{\text {th }}$ catalytic run confirmed that the molecular connectivity, chemical environment with structural integrity of the Ph-POP framework remains intact in nature, signifying to the high mechanical and chemical stability of the catalyst. In the hotfiltration test robust nature of the catalyst with minimal leaching of Pd was evaluated. We have achieved $20 \%$ selectivity of EB with $75 \%$ conversion of AP after 10 minutes. We could not reach EB selectivity (\%) beyond this when additional reaction was carried out for $1 \mathrm{~h}$ with only reaction mixture/filtrate after separation of solid catalyst. We have analyzed $\mathrm{Pd}$ content present in the catalyst in each catalytic cycle by ICP-AES analysis (Table S3, SI). The result unambiguously states that Pd atoms hardly were leached into the reaction medium as 3D rigid hydroxyl enriched $\mathrm{Ph}$-POP network wrap the catalytic active sites more robustly and thereby inhibiting metal ions detachment during reaction. Additionally, for clear understanding the difference in the structure and acetophenone (AP) hydrodeoxygenation reactivity of our synthesized catalyst with previous reported catalysts, we have done comparison (Table S4, SI) study and explained thoroughly.

\section{CONCLUSIONS:}

In summary, we have successfully developed and synthesized palladium (Pd) nanoparticles encapsulated in flexible hydroxyl (-OH) enriched porous-organic-polymer (Ph-POP) nanocages via polymer formation through condensation of phloroglucinol and terephthalaldehyde followed by addition and reduction of the metal precursor with hydrogen. The newly designed catalyst exhibits excellent catalytic performance compared to $\mathrm{Pd} @ \mathrm{Al}_{2} \mathrm{O}_{3}$ towards liquid-phase hydrodeoxygenation (HDO) of acetophenone contributing complete conversion and $100 \%$ ethyl benzene selectivity under very low pressure $(0.5$ bar $)$ and reaction temperature $\left(60{ }^{\circ} \mathrm{C}\right)$. The superior activity of Pd@Ph-POP originated from the modulation of electronic properties of $\mathrm{Pd}$ through electron donation from the oxygen unit of the highly oxygen enriched Ph-POP framework. The impressive product selectivity of this catalyst could be attributed to higher support acidity of polymer unit promoting the dehydration of 1phenylethanol to ethylbenzene. To gain more mechanistic information, in situ ATR-IR spectroscopic experiment was performed, which revealed that desorption of our final product EB can easily be done in a solution of $\mathrm{Pd} @ \mathrm{Ph}-\mathrm{POP}$ nanocage compared with the $\mathrm{Pd} @ \mathrm{Al}_{2} \mathrm{O}_{3}$ counterpart, suggested by the much weaker but better resolved signal at $1494 \mathrm{~cm}^{-}$ 
${ }^{1}$ characterized for EB in the ATR-IR spectra of Pd@Ph-POP was the key factor for the adequate catalytic hydrogen transfer mechanism. Another crucial fact that the Ph-POP framework was less prone to coordinate organic molecule than its $\mathrm{Al}_{2} \mathrm{O}_{3}$ counterpart was also established from ATR-IR study. Detailed insights into the unprecedented high activity and selectivity of Pd@Ph-POP catalyst in the HDO conversion of acetophenone (AP) towards Ethyl Benzene (EB) were also revealed from density functional theory (DFT) calculations. Three different hydrogenation routes for the conversion of AP to PhE were evaluated comprehensively, including the direct surface hydrogen route, the enol route and the hydrogen transfer route. The computed activation barrier for an initial hydrogenation-activation of AP by those routes were 74, 86 and $38 \mathrm{~kJ} / \mathrm{mol}$, respectively, and all those routes produced the same product after the first step-the hydroxy-alkyl intermediate. The next hydrogenation of this intermediate forming $\mathrm{PhE}$ was facilitated by direct surface hydrogen route. Once $\mathrm{PhE}$ was formed, the high barrier of $124 \mathrm{~kJ} / \mathrm{mol}$ hinders the subsequent dehydroxylation reaction, explaining the low selectivity towards ethylebenzene on $\mathrm{Pd} @ \mathrm{Al}_{2} \mathrm{O}_{3}$ catalyst. Phenolic hydroxyl groups of the Ph-POP frame-structure stabilized the water molecules in the vicinity near the Pd-NPs surface, opened an alternative low-barrier reaction pathway for the dehydration of the key intermediate phenyl ethanol via the hydrogen shuttling mechanism, facilitating the formation of the final product ethylbenzene. Besides, the strong interaction between Pd-NPs and aromatic rings of Ph-POP also weaken the binding of ethyl benzene and reduce the coverage of surface hydrogen atoms on Pd@Ph-POP, both hindering the over-hydrogenation reaction of the desired product ethyl benzene and contributing to the high selectivity of EB generated during the HDO conversion of AP on Pd@Ph-POP in this study. Furthermore, the catalyst displayed improved stability, preserving AP hydrogenation activity and ethyl benzene selectivity over 10 successive catalytic runs, which is attributed to the encapsulation of Pd-NPs in the 3D rigid hydroxyl enriched Ph-POP network. The present results demonstrate the need to develop further this and other electron rich Ph-POP supported Pd-NPs catalysts towards selective hydrogenation to produce value added chemicals.

\section{ASSOCIATED CONTENT.}

\section{Supporting Information.}

Characterization details, TGA, Wide-angle powder XRD patterns, elemental analysis (EA), $\mathrm{NH}_{3}$-TPD, ATR-IR spectra of pyridine adsorption, TEM images, Particle size distribution 
histogram profile, Energy dispersive X-ray (EDX), XPS survey spectrum, the possible reaction pathway, Effect of solvents, Screening of various Pd based catalysts, Recycle Potential diagram for chemoselective hydrogenation of acetophenone, SEM images of reused catalyst, Particle size distribution histogram profile of reused catalysts, Solid state ${ }^{13}$ C-CP MAS NMR spectrum of reused catalyst, ICP-OES analysis of reused Pd@Ph-POP catalyst. DFT structures of other transitions states during the HDO conversion of AP to EB on $\operatorname{Pd}(111)$ surfaces, the adsorption of reactant (AP) and products (EB) on $\mathrm{Pd}(111)$ surface with pre-adsorbed Phenol, the dehydrogenation of isopropanol on $\mathrm{Pd}(111)$ and others reaction along the hydrogen transfer route. The stability between keto-enol form of acetophenone, and the hydrogen transfer between acetophenone and isopropanol in liquid phase without the Pd catalyst by Gaussian simulations.

\section{AUTHOR INFORMATION.}

\section{Corresponding Authors}

*E-mail: trinhquangthang @duytan.edu.vn (Q.T.T.).

*E-mail: johncuchem@gmail.com; johnmondal@iict.res.in (J.M.)

\section{ORCID.}

Quang Thang Trinh: 0000-0002-3311-4691

Matthew P. Sherburne: 0000-0002-3992-1822

Davide Ferri:0000-0002-9354-5231

John Mondal: 0000-0001-7813-2108

Duy Quang Dao: 0000-0003-0896-5168

Quyet Van Le: 0000-0002-4313-301X

G. T. Kasun Kalhara Gunasooriya: 0000-0003-1258-7841

\section{Author Contributions.}

${ }^{\#}$ R. P. and S.C.S. have equally contributed.

\section{Notes}

The authors declare no competing financial interest.

\section{ACKNOWLEDGMENTS.}


R.P. and S.C.S. acknowledge the DST-INSPIRE (GAP-0799) \& Council of Scientific and Industrial Research (CSIR), New Delhi, for their respective junior \& senior research fellowships. J.M. acknowledges the Department of Science and Technology, India, for the DSTINSPIRE Faculty Research project grant (GAP-0522) \& CSIR-YSA Research Grant (Reference no: HRDG/YSA-19/02/21(0045)/2019) for financial support at CSIR-IICT, Hyderabad. We thank Director, CSIR-IICT (Ms. No. IICT/Pubs./2019/271) for providing all the required facilities to carry out the work. The authors are also grateful to Dr. Kazuhide Kamiya and Dr. Takashi Harada, Research Center for Solar Energy Chemistry, Osaka University, Japan for acquiring ${ }^{13} \mathrm{C}$ CP solid state MAS NMR, TEM, XPS and SEM measurements, respectively. Q.T.T. and M.P.S. acknowledge the financial support by the Singapore National Research Foundation under its Campus for Research Excellence and Technological Enterprise (CREATE) program through the Cambridge Center for Carbon Reduction in Chemical Technology $(\mathrm{C} 4 \mathrm{~T})$ and $\mathrm{eCO}_{2} \mathrm{EP}$ programs. The computational work for this article was fully performed on resources of the National Supercomputing Centre, Singapore (https://www.nscc.sg) under the projects ID 12000902 and 12001929. T.F. and D.F. acknowledge the financial support from PSI through a CROSS project. Dr. Quyet Van Le was supported by Korea Research Fellowship Program through the National Research Foundation of Korea (NRF) funded by the Ministry of Science and ICT (grant number 2020H1D3A1A04081409).

\section{REFERENCES.}

(1) Amaniampong, P. N.; Asiedu, N. Y.; Fletcher, E.; Dodoo-Arhin, D.; Olatunji, O. J.; Trinh, Q. T. Conversion of Lignocellulosic Biomass to Fuels and Value-Added Chemicals Using Emerging Technologies and State-of-the-Art Density Functional Theory Simulations Approach. In Valorization of Biomass to Value-Added Commodities: Current Trends, Challenges, and Future Prospects; Daramola M. O.; Ayeni, A. O., Eds.; Springer International Publishing, Cham, 2020, 193-220.

(2) Kashiwagi, Y.; Uchiyama, K.; Kurashima, F.; Kikuchi, C.; Anzai, J.-i. Chiral Discrimination in Electrocatalytic Oxidation of (R)- and (S)-1-Phenylethanol using a Chiral Nitroxyl Radical as Catalyst. Chem. Pharm. Bull. 1999, 47, 1051-1052.

(3) Lee, E. H. Iron Oxide Catalysts for Dehydrogenation of Ethylbenzene in the Presence of Steam. Catal. Rev. Sci. Eng. 1974, 8, 285-305.

(4) Fujita, S.-i.; Onodera, Y.; Yoshida, H.; Arai, M. Selective Hydrogenation of Acetophenone with Supported Pd and Rh Catalysts in Water, Organic Solvents, and $\mathrm{CO}_{2}-$ Dissolved Expanded Liquids. Green Chem. 2016, 18, 4934-4940. 
(5) Chen, M.; Maeda, N.; Baiker, A.; Huang, J. Molecular Insight into Pt-Catalyzed Chemoselective Hydrogenation of an Aromatic Ketone by In Situ Modulation-Excitation IR Spectroscopy. ACS Catal. 2012, 2, 2007-2013.

(6) Hiyoshi, N.; Sato, O.; Yamaguchi, A.; Shirai, M. Acetophenone Hydrogenation Over a Pd Catalyst in the Presence of $\mathrm{H}_{2} \mathrm{O}$ and $\mathrm{CO}_{2}$. Chem. Commun. 2011, 47, 11546-11548.

(7) Duraczyńska, D.; Drelinkiewicz, A.; Bielańska, E.; Serwicka, E. M.; LityńskaDobrzyńska, L. Hydrogenation of Acetophenone in the Presence of Ru Catalysts Supported on Amine Groups Functionalized Polymer. Catal. Lett. 2011, 141, 83-94.

(8) Kannapu, H. P. R.; Suh, Y.-W.; Narani, A.; Vaddeboina, V.; Burri, D. R.; Kamaraju Seetha, R. R. One-pot Synthesis of Ethylbenzene/1-Phenylethanol and $\gamma$-butyrolactone from Simultaneous Acetophenone Hydrogenation and 1,4-Butanediol Dehydrogenation over Copper Based Catalysts: Effects of the Support. RSC Adv. 2017, 7, 35346-35356.

(9) Asensio, J. M.; Miguel, A. B.; Fazzini, P.-F.; van Leeuwen, P. W. N. M.; Chaudret, B. Hydrodeoxygenation using Magnetic Induction: High-Temperature Heterogeneous Catalysis in Solution. Angew.Chem. Int.Ed. 2019, 58, 11306-11310.

(10) Hoxha, F.; Schimmoeller, B.; Cakl, Z.; Urakawa, A.; Mallat, T.; Pratsinis, S. E.; Baiker, A. Influence of Support Acid-Base Properties on the Platinum-Catalyzed Enantioselective Hydrogenation of Activated Ketones. J. Catal. 2010, 271, 115-124.

(11) Chen, C.-S.; Chen, H.-W. Enhanced Selectivity and Formation of Ethylbenzene for Acetophenone Hydrogenation by Adsorbed Oxygen on $\mathrm{Pd} / \mathrm{SiO}_{2}$. Appl. Catal. A, General 2004, 260, 207-213.

(12) Chen, M.; Maeda, N.; Baiker, A.; Huang, J. Hydrogenation of Acetophenone on $\mathrm{Pd} /$ Silica-Alumina Catalysts with Tunable Acidity: Mechanistic Insight by In Situ ATR-IR Spectroscopy. ACS Catal. 2018, 8, 6594-6600.

(13) Mondal, J.; Paul, R.; Sarkar, C.; Yan, Y.; Trinh, Q. T.; Rao, B. S.; Pao, C.-W.; Lee, J.F.; Liu, W. Porous-Organic-Polymer-Triggered Advancement of Sustainable Magnetic Efficient Catalyst for Chemoselective Hydrogenation of Cinnamaldehyde. ChemCatChem 2020, 12, 3687-3704.

(14) Shit, S. C.; Khilari, S.; Mondal, I.; Pradhan, D.; Mondal, J. The Design of a New Cobalt Sulfide Nanoparticle Implanted Porous Organic Polymer Nanohybrid as a Smart and Durable Water-Splitting Photoelectrocatalyst. Chem. Eur. J. 2017, 23, 14827-14838.

(15) Shit, S. C.; Koley, P.; Joseph, B.; Marini, C.; Nakka, L.; Tardio, J.; Mondal, J. Porous Organic Polymer-Driven Evolution of High-Performance Cobalt Phosphide Hybrid Nanosheets as Vanillin Hydrodeoxygenation Catalyst. ACS Appl. Mater. Interfaces 2019, 11, 24140-24153.

(16) Singuru, R.; Dhanalaxmi, K.; Shit, S. C.; Reddy, B. M.; Mondal, J. Palladium Nanoparticles Encaged in a Nitrogen-Rich Porous Organic Polymer: Constructing a Promising Robust Nanoarchitecture for Catalytic Biofuel Upgrading. ChemCatChem 2017, 9, 2550-2564.

(17) Sarkar, C.; Pendem, S.; Shrotri, A.; Dao, D. Q.; Pham Thi Mai, P.; Nguyen Ngoc, T.; Chandaka, D. R.; Rao, T. V.; Trinh, Q. T.; Sherburne, M. P.; Mondal, J. Interface Engineering of Graphene-Supported $\mathrm{Cu}$ Nanoparticles Encapsulated by Mesoporous Silica for Size-Dependent Catalytic Oxidative Coupling of Aromatic Amines. ACS Appl. Mater. Interfaces 2019, 11, 11722-11735. 
(18) Lu, W.; Bosch, M.; Yuan, D.; Zhou, H.-C. Cost-Effective Synthesis of Amine-Tethered Porous Materials for Carbon Capture. ChemSusChem 2015, 8, 433-438,.

(19) Baurecht, D.; Fringeli, U. P. Quantitative Modulated Excitation Fourier Transform Infrared Spectroscopy. Rev. Sci. Instrum. 2001, 72, 3782-3792.

(20) Kresse, G.; Furthmüller, J. Efficiency of AB-initio Total Energy Calculations for Metals and Semiconductors Using a Plane-Wave Basis Set. Comput. Mater. Sci. 1996, 6, 15-50.

(21) Kresse, G. Ab initio Molecular Dynamics for Liquid Metals. J. Non-Cryst. Solids 1995, 192-193, 222-229.

(22) Trinh, Q. T.; Nguyen, A. V.; Huynh, D. C.; Pham, T. H.; Mushrif, S. H. Mechanistic Insights into the Catalytic Elimination of Tar and the Promotional Effect of Boron on it: First-Principles Study using Toluene as a Model Compound. Catal. Sci. Technol. 2016, 6, 5871-5883.

(23) Yildirim, H.; Greber, T.; Kara, A. Trends in Adsorption Characteristics of Benzene on Transition Metal Surfaces: Role of Surface Chemistry and Van der Waals Interactions. The J. Phys. Chem. C 2013, 117, 20572-20583.

(24) Klimeš, J.; Bowler, D. R.; Michaelides, A. Van der Waals Density Functionals Applied to Solids. Phys. Rev. B 2011, 83, 195131.

(25) Trinh, Q. T.; Chethana, B. K.; Mushrif, S. H. Adsorption and Reactivity of Cellulosic Aldoses on Transition Metals. J. Phys. Chem. C 2015, 119, 17137-17145.

(26) Trinh, Q. T.; Yang, J.; Lee, J. Y.; Saeys, M. Computational and Experimental Study of the Volcano Behavior of the Oxygen Reduction Activity of PdM@PdPt/C (M=Pt, Ni, Co, Fe, and Cr) Core-Shell Electrocatalysts. J. Catal. 2012, 291, 26-35.

(27) Sarkar, C.; Shit, S. C.; Dao, D. Q.; Lee, J.; Tran, N. H.; Singuru, R.; An, K.; Nguyen, D. N.; Le, Q. V.; Amaniampong, P. N.; Drif, A.; Jerome, F.; Huyen, P. T.; Phan, T. T. N.; Vo, D.-V. N.; Thanh Binh, N.; Trinh, Q. T.; Sherburne, M. P.; Mondal, J. An Efficient Hydrogenation Catalytic Model Hosted in a Stable Hyper-Crosslinked Porous-OrganicPolymer: from Fatty Acid to Bio-Based Alkane Diesel Synthesis. Green Chem. 2020, 22, 2049-2068.

(28) Trinh, Q. T.; Banerjee, A.; Yang, Y.; Mushrif, S. H. Sub-Surface Boron-Doped Copper for Methane Activation and Coupling: First-Principles Investigation of the Structure, Activity, and Selectivity of the Catalyst. J. Phys. Chem. C 2017, 121, 1099-1112.

(29) Henkelman, G.; Uberuaga, B. P.; Jónsson, H. A Climbing Image Nudged Elastic Band Method for Finding Saddle Points and Minimum Energy Paths. J. Chem. Phys. 2000, 113, 9901-9904.

(30) Katsoulidis, A. P.; Kanatzidis, M. G. Phloroglucinol Based Microporous Polymeric Organic Frameworks with -OH Functional Groups and High $\mathrm{CO}_{2}$ Capture Capacity. Chem. Mater. 2011, 23, 1818-1824.

(31) Lu, W.; Yuan, D.; Zhao, D.; Schilling, C. I.; Plietzsch, O.; Muller, T.; Bräse, S.; Guenther, J.; Blümel, J.; Krishna, R.; Li, Z.; Zhou, H.-C. Porous Polymer Networks: Synthesis, Porosity, and Applications in Gas Storage/Separation. Chem. Mater. 2010, 22, 5964-5972.

(32) Huang, Z.; Liu, S.; Xu, J.; Yin, L.; Zheng, J.; Zhou, N.; Ouyang, G. Porous Organic Polymers with Different Pore Structures for Sensitive Solid-phase Microextraction of Environmental Organic Pollutants. Anal. Chim. Acta 2017, 989, 21-28. 
(33) Qi, B.; Di, L.; Xu, W.; Zhang, X. Dry Plasma Reduction to Prepare a High Performance $\mathrm{Pd} / \mathrm{C}$ Catalyst at Atmospheric Pressure for CO Oxidation. J. Mater. Chem. A 2014, 2, 1188511890.

(34) Zhang, J.; Gao, K.; Wang, S.; Li, W.; Han, Y. Performance of Bimetallic PdRu Catalysts Supported on Gamma Alumina for 2-Ethylanthraquinone Hydrogenation. RSC Adv. 2017, 7, 6447-6456.

(35) Wang, G.-H.; Hilgert, J.; Richter, F. H.; Wang, F.; Bongard, H.-J.; Spliethoff, B.; Weidenthaler, C.; Schüth, F. Platinum-Cobalt Bimetallic Nanoparticles in Hollow Carbon Nanospheres for Hydrogenolysis of 5-Hydroxymethylfurfural. Nat. Mater. 2014, 13, 293300 .

(36) Jia, Z.; Li, C.; Liu, D.; Jiang, L. Direct Hydrothermal Reduction of Graphene Oxide Based Papers Obtained from Tape Casting for Supercapacitor Applications. RSC Adv. 2015, $5,81030-81037$.

(37) Yan, H.; Li, Y.; Guo, X.; Zhou, M.; Wang, H.-Q.; Dai, Y.; Zheng, J.-C. Synergistic Supercritical Water 'Wet' Activated Biomass Carbon as High Performances Electrode Materials for Supercapacitor. J. Electrochem. Soc. 2018, 165, A2075-A2083.

(38) Zhang, R.; Wan, W.; Qiu, L.; Wang, Y.; Zhou, Y. Preparation of Hydrophobic Polyvinyl Alcohol Aerogel via the Surface Modification of Boron Nitride for Environmental Remediation. Appl. Surf. Sci. 2017, 419, 342-347.

(39) Mondal, J.; Trinh, Q. T.; Jana, A.; Ng, W. K. H.; Borah, P.; Hirao, H.; Zhao, Y. SizeDependent Catalytic Activity of Palladium Nanoparticles Fabricated in Porous Organic Polymers for Alkene Hydrogenation at Room Temperature. ACS Appl. Mater. Interfaces 2016, $8,24,15307-15319$.

(40) Wang, C.; Yang, F.; Yang, W.; Ren, L.; Zhang, Y.; Jia, X.; Zhang, L.; Li, Y. PdO Nanoparticles Enhancing the Catalytic Activity of Pd/Carbon Nanotubes for 4-Nitrophenol Reduction. RSC Adv. 2015, 5, 27526-27532.

(41) Shit, S. C.; Singuru, R.; Pollastri, S.; Joseph, B.; Rao, B. S.; Lingaiah, N.; Mondal, J. $\mathrm{Cu}-\mathrm{Pd}$ Bimetallic Nanoalloy Anchored on a N-Rich Porous Organic Polymer for HighPerformance Hydrodeoxygenation of Biomass-Derived Vanillin. Catal. Sci. Technol. 2018, 8, 2195-2210.

(42) Koley, P.; Rao, B. S.; Sabri, Y. M.; Bhargava, S. K.; Tardio, J.; Nakka, L. Selective Conversion of Furfural into Tetrahydrofurfuryl Alcohol using a Heteropoly Acid-Based Material as a Hydrogenation Catalyst. Sustain. Energy Fuels 2020, 4, 4768-4779.

(43) Ferri, D.; Frauchiger, S.; Bürgi, T.; Baiker, A. Interactions of a Vinyl Ether with AcidModified Silica-Based Catalyst Studied by ATR-IR Spectroscopy. J. Catal. 2003, 219, 425433.

(44) Alonso, F.; Riente, P.; Yus, M. Hydrogen-Transfer Reduction of Carbonyl Compounds Catalysed by Nickel Nanoparticles. Tetrahedron Lett. 2008, 49, 1939-1942.

(45) Alonso, F.; Riente, P.; Sirvent, J. A.; Yus, M. Nickel Nanoparticles in HydrogenTransfer Reductions: Characterisation and Nature of the Catalyst. Appl. Catal. A, General 2010, 378, 42-51.

(46) De Vrieze, J. E.; Urbina Blanco, C. A.; Thybaut, J. W.; Saeys, M. Autocatalytic Role of Molecular Hydrogen in Copper-Catalyzed Transfer Hydrogenation of Ketones. ACS Catal. 2019, 9, 8073-8082. 
(47) Kundu, S. K.; Bhaumik, A. Pyrene-Based Porous Organic Polymers as Efficient Catalytic Support for the Synthesis of Biodiesels at Room Temperature. ACS Sustainable Chem. Eng. 2015, 3, 1715-1723.

(48) Hensley, A. J. R.; Wang, Y.; McEwen, J.-S. Adsorption of Phenol on Fe (110) and Pd (111) from First Principles. Surf. Sci. 2014, 630, 244-253

(49) Dong, W.; Hafner, J. $\mathrm{H}_{2}$ Dissociative Adsorption on $\mathrm{Pd}(111)$. Phys. Rev. B 1997, 56, 15396-15403.

(50) Trinh, Q. T.; Banerjee, A.; Ansari, K. B.; Dao, D. Q.; Drif, A.; Binh, N. T.; Tung, D. T.; Binh, P. M. Q.; Amaniampong, P. N.; Huyen, P. T.; Le, M. T. Upgrading of Bio-oil from Biomass Pyrolysis: Current Status and Future Development. In Biorefinery of Alternative Resources: Targeting Green Fuels and Platform Chemicals; Nanda, S.; N. Vo, D.-V.; Sarangi, P. K., Eds.; Springer Singapore: Singapore, 2020, 317-353.

(51) Nørskov, J. K.; Studt, F.; Abild $\square$ Pedersen, F.; Bligaard, T. Rate Constants. In Fundamental Concepts in Heterogeneous Catalysis; Nørskov, J. K.; Studt, F.; Abild $\square$ Pedersen, F.; Bligaard, T., Eds.; John Wiley \& Sons, Inc: 2014, 4, 47-67.

(52) Hibbitts, D. D.; Loveless, B. T.; Neurock, M.; Iglesia, E. Mechanistic Role of Water on the Rate and Selectivity of Fischer-Tropsch Synthesis on Ruthenium Catalysts. Angew. Chem. Int. Ed. 2013, 52, 12273-12278.

(53) Gunasooriya, G. T. K. K.; van Bavel, A. P.; Kuipers, H. P. C. E.; Saeys, M. Key Role of Surface Hydroxyl Groups in C-O Activation during Fischer-Tropsch Synthesis. ACS Catal. 2016, 6, 3660-3664.

(54) Amaniampong, P. N.; Trinh, Q. T.; Wang, B.; Borgna, A.; Yang, Y.; Mushrif, S. H. Biomass Oxidation: Formyl C-H Bond Activation by the Surface Lattice Oxygen of Regenerative $\mathrm{CuO}$ Nanoleaves. Angew. Chem. Int. Ed. 2015, 54, 8928-8933.

(55) Amaniampong, P. N.; Trinh, Q. T.; De Oliveira Vigier, K.; Dao, D. Q.; Tran, N. H.; Wang, Y.; Sherburne, M. P.; Jérôme, F. Synergistic Effect of High-Frequency Ultrasound with Cupric Oxide Catalyst Resulting in a Selectivity Switch in Glucose Oxidation under Argon. J. Am. Chem. Soc. 2019, 141, 14772-14779.

(56) Singh, N.; Campbell, C. T. A Simple Bond-Additivity Model Explains Large Decreases in Heats of Adsorption in Solvents Versus Gas Phase: A Case Study with Phenol on Pt(111) in Water. ACS Catal. 2019, 9, 8116-8127.

(57) Singuru, R.; Trinh, Q. T.; Banerjee, B.; Govinda Rao, B.; Bai, L.; Bhaumik, A.; Reddy, B. M.; Hirao, H.; Mondal, J. Integrated Experimental and Theoretical Study of ShapeControlled Catalytic Oxidative Coupling of Aromatic Amines over CuO Nanostructures. ACS Omega 2016, 1, 1121-1138.

(58) Gunasooriya, G. T. K. K.; Seebauer, E. G.; Saeys, M. Ethylene Hydrogenation over Pt/TiO2: A Charge-Sensitive Reaction. ACS Catal. 2017, 7, 1966-1970.

(59) Attia, S.; Schmidt, M.-C.; Schröder, C.; Pessier, P.; Schauermann, S. Surface-Driven Keto-Enol Tautomerization: Atomistic Insights into Enol Formation and Stabilization Mechanisms. Angew. Chem. Int. Ed. 2018, 57, 16659-16664.

(60) De Vrieze, J. E.; Thybaut, J. W.; Saeys, M. Role of Keto-Enol Tautomerization in the Copper-Catalyzed Hydrogenation of Ketones. ACS Catal. 2019, 9, 3831-3839. 
(61) Attia, S.; Schmidt, M. C.; Schröder, C.; Weber, J.; Baumann, A.-K.; Schauermann, S. Keto-Enol Tautomerization as a First Step in Hydrogenation of Carbonyl Compounds. $J$. Phys. Chem. C 2019, 123, 29271-29277.

(62) Vila, F.; López Granados, M.; Mariscal, R. Significance of Isomeric Reaction Intermediates in the Hydrogenolysis of Glycerol to 1,2-Propanediol with $\mathrm{Cu}$-based Catalysts. Catal. Sci. Technol. 2017, 7, 3119-3127.

(63) Rasmussen, A. M. H.; Groves, M. N.; Hammer, B. Remote Activation of Chemical Bonds in Heterogeneous Catalysis. ACS Catal. 2014, 4, 1182-1188.

(64) Chang, X.; Liu, A.-F.; Cai, B.; Luo, J.-Y.; Pan, H.; Huang, Y.-B. Catalytic Transfer Hydrogenation of Furfural to 2-Methylfuran and 2-Methyltetrahydrofuran over Bimetallic Copper-Palladium Catalysts. ChemSusChem 2016, 9, 3330-3337.

(65) Subramanian, T.; Pitchumani, K. Transfer Hydrogenation of Carbonyl Compounds and Carbon-Carbon Multiple Bonds by Zeolite Supported Cu Nanoparticles. Catal. Sci. Technol. 2012, 2, 296-300.

(66) Bertero, N. M.; Trasarti, A. F.; Apesteguía, C. R.; Marchi, A. J. Solvent Effect in the Liquid-Phase Hydrogenation of Acetophenone over $\mathrm{Ni} / \mathrm{SiO}_{2}$ : A Comprehensive Study of the Phenomenon. Appl. Catal. A, General 2011, 394, 228-238.

(67) Koley, P.; Shit, S. C.; Joseph , B.; Pollastri, S.; Sabri, Y. M.; Mayes, E. L.; Nakka , L.; Tardio, J.; Mondal J. Leveraging $\mathrm{Cu} / \mathrm{CuFe}_{2} \mathrm{O}_{4}$-Catalyzed Biomass-Derived Furfural Hydrodeoxygenation: A Nanoscale Metal-Organic-Framework Template Is the Prime Key. ACS Appl. Mater. Interfaces 2020, 12, 21682-21700

(68) Shit, S. C.; Mondal, I.; Saikiran, P.; Bai, L.; Park, J. Y.; Mondal, J. MOF-derived BiFunctional Iron Oxide and Iron Phosphide Nanoarchitecture Photoelectrode for Neutral Water Splitting. ChemElectroChem 2018, 5, 2842-2849. 


\section{Graphical Abstract:}

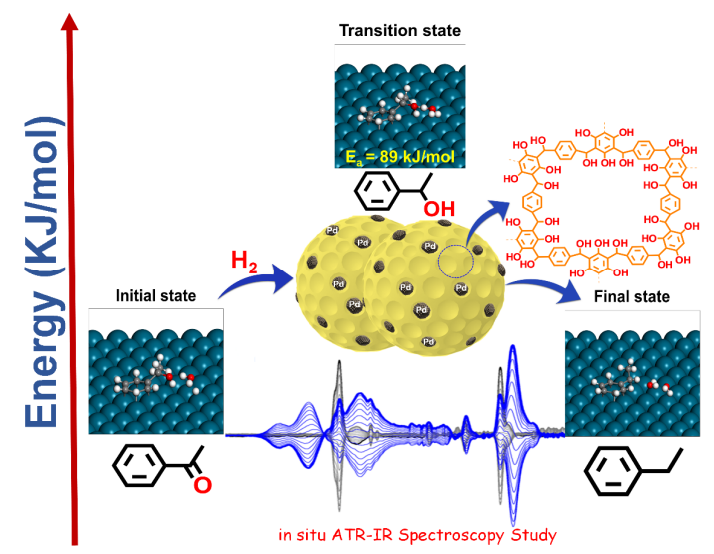

